\title{
Citation analysis of the most influential ependymoma research articles illustrates improved knowledge of the molecular biology of ependymoma
}

\author{
Nolan J. Brown ${ }^{1}$ (D $\cdot$ Bayard Wilson ${ }^{2} \cdot$ Brian V. Lien $^{1} \cdot$ Alexander Himstead $^{1} \cdot$ Ali R. Tafreshi $^{3} \cdot$ Shane Shahrestani $^{4,5}$. \\ Jack Birkenbeuel ${ }^{1} \cdot$ Katelynn Tran $^{1}$ - David Horton ${ }^{1} \cdot$ Anushka Paladugu $^{1} \cdot$ Lydia R. Kirillova $^{1} \cdot$ Chen Yi Yang $^{1}$. \\ Seth C. Ransom ${ }^{6} \cdot$ Ronald Sahyouni $^{7}$. Isaac Yang $8,9,10,11,12,13,14$
}

Received: 8 February 2021 / Revised: 15 May 2021 / Accepted: 7 June 2021 / Published online: 6 October 2021

(c) The Author(s) 2021

\begin{abstract}
The history of academic research on ependymoma is expansive. This review summarizes its history with a bibliometric analysis of the 100 most cited articles on ependymoma. In March 2020, we queried the Web of Science database to identify the most cited articles on ependymoma using the terms "ependymoma" or "ependymal tumors," yielding 3145 publications. Results were arranged by the number of times each article was cited in descending order. The top 100 articles spanned across nearly a century; the oldest article was published in 1924, while the most recent was in 2017. These articles were published in 35 unique journals, including a mix of basic science and clinical journals. The three institutions with the most papers in the top 100 were St. Jude Children's Research Hospital (16\%), the University of Texas MD Anderson Cancer Center (6\%), and the German Cancer Research Center (5\%). We analyzed the publications that may be considered the most influential in the understanding and treatment management of ependymoma. Studies focused on the molecular classification of ependymomas were well-represented among the most cited articles, reflecting the field's current area of focus and its future directions. Additionally, this article also offers a reference for further studies in the ependymoma field.
\end{abstract}

Keywords Ependymoma $\cdot$ Ependymal tumors $\cdot$ Citation analysis $\cdot$ Bibliometric analysis

Nolan J. Brown, Bayard Wilson, Brian V. Lien and Alexander

Himstead these authors contributed equally.

Nolan J. Brown

nolanb@hs.uci.edu

1 Department of Neurological Surgery, University of California, Irvine, CA, USA

2 Department of Neurological Surgery, University of California, Los Angeles, CA, USA

3 Department of Neurological Surgery, Geisinger Health System, Danville, PA, USA

4 Medical Scientist Training Program, California Institute of Technology, Pasadena, CA, USA

5 Keck School of Medicine of USC, Los Angeles, CA, USA

6 College of Medicine, University of Arkansas for Medical Sciences, Little Rock, AR, USA

7 Department of Neurological Surgery, University of California, San Diego, La Jolla, CA, USA
8 Department of Neurosurgery, Los Angeles (UCLA), Los Angeles, CA, USA

9 Head and Neck Surgery, Los Angeles (UCLA), Los Angeles, CA, USA

10 Radiation Oncology, Los Angeles (UCLA), Los Angeles, CA, USA

11 Jonsson Comprehensive Cancer Center, Los Angeles (UCLA), Los Angeles, CA, USA

12 Los Angeles Biomedical Research Institute, Los Angeles (UCLA), Los Angeles, CA, USA

13 Harbor-UCLA Medical Center, Los Angeles (UCLA), Los Angeles, CA, USA

14 David Geffen School of Medicine, Los Angeles (UCLA), Los Angeles, CA, USA 


\section{Introduction}

Ependymomas are rare primary tumors of the central nervous system (CNS) that affect both children and adults [40, 42]. The 2016 World Health Organization (WHO) Classification of Tumors of the CNS categorizes them into four subtypes: subependymoma and myxopapillary ependymoma (grade I), ependymoma (grade II), ependymoma RELA (v-rel avian reticuloendotheliosis viral oncogene homolog A) fusion-positive (grade II or III), and anaplastic ependymoma (grade III) [12, 58]. Ependymomas are more commonly found in children and at this age more likely to be located intracranially and harbor more aggressive molecular variants, leading to worse overall survival (OS) when compared to adult variants [6, 14, 28, 30, 55].

Ependymomas have been extensively studied with respect to molecular subtyping, prognostication, and clinical outcomes $[4,8$, $14,30,56,58]$. Therapy focuses on strategic surgical approaches to achieve gross total resection (GTR), and conformal radiation therapy (CRT) is the most common adjunctive treatment $[6,20$, $21,24,38,49]$. Chemotherapy has been studied primarily in children under 3 years of age due to their susceptibility to radiotherapy-induced neurotoxicity. However, chemotherapy has failed to demonstrate improved outcomes compared to CRT [53]. At present, several clinical trials are underway scrutinizing promising neoadjuvant chemotherapeutic strategies [13, 32, 53]. Presently, effective treatment of ependymoma requires a multi-modal approach, involving an interdisciplinary team of neurosurgeons, neurologists, oncologists, radiologists, and primary care physicians, among others [14, 29]. Prognosis varies by type and location; pediatric ependymomas are more commonly intracranial with a 10-year estimated survival rate of $13-50 \%$, while adult ependymomas have a predilection for the spine and have a 5-year survival rate of 67 to $85 \%$ and a 10-year survival rate of $72 \%$ $[14,30,37]$. In both populations, complete resection is the most consistent factor correlated with improved outcomes $[6,14,37]$.

Given the diversity, volume, and interdisciplinary nature of ependymoma research, a bibliometric analysis focused on the history, recent developments, and trajectory of research can help frame our current understanding of the disease [3, 17]. The objective of this study is to analyze the most influential articles on ependymoma and identify the most relevant clinical problems in the field to guide further investigation. While bibliometric analyses have been published for neoplastic lesions of the brain $[2,3,7,17,25]$ and for the spinal cord $[1,9,10]$, no such investigation currently exists for ependymoma.

\section{Methods}

On March 22, 2020, we performed a title-specific search of the Thomson Reuters Web of Science (WoS) database (Thomson Reuters, NY, USA) to identify the most cited articles on ependymoma. We used "ependymoma" or "ependymal tumors" as our query term for the years 1900 to 2020 selecting the "all databases" option. The results were arranged according to the number of times each article was cited in descending order. To avoid the subjective exclusion of studies from our analysis, all papers from our query were included if they were ranked 1 to 100 in terms of number of total citations. The following variables were extracted: rank of article by total citations, rank of article by average citations per year, first and last author, title of article, publication, year, total citations for each article, average citations per year for each article, article country of origin, and institution of the first author. In cases of co-first authorship, country and institution of the author listed first were used [3, 7, 17, 31]. The average citations per year for each article was calculated as previously described [10].

We categorized the articles as either clinical, basic science, or literature review. Articles were independently classified by LRK and DH and reexamined by BVL and AP. Any inconsistencies were resolved by discussion with the senior author (IY) after careful review of full-text articles. Studies that were primarily focused on basic tumor biology or molecular classification of ependymoma were classified as basic science (e.g., involving genome sequencing) as described previously [25]. Studies that were patientfocused and reported outcomes were classified as clinical, which included histopathological studies [25].

\section{Results}

Our query yielded 3145 publications on ependymoma. The top 100 most cited articles were selected for review based on overall citation count and are shown in Tables 1 and 2, organized by total citations and average citations per year, respectively. These articles were published between 1924 and 2017. They have been cited a collective 11,640 times, averaging 116.4 citations per article (Table 1). The top 10 articles on the list were published between 1977 and 2015 and averaged 304 total citations (standard deviation [SD], 106.5; range, 206-551) (Table 1).

The most cited article overall was a basic science article entitled "Radial glia cells are candidate stem cells of ependymoma," published in Cancer Cell in 2005 (Table 3) [51]. The second most cited article overall was a clinical article entitled "Intramedullary ependymoma of the spinal cord," published in the Journal of Neurosurgery in 1990 (Table 4) [34]. Basic science and clinical articles comprised the majority of the top 50 . The first review article ranked forty-second overall was titled "Pediatric 


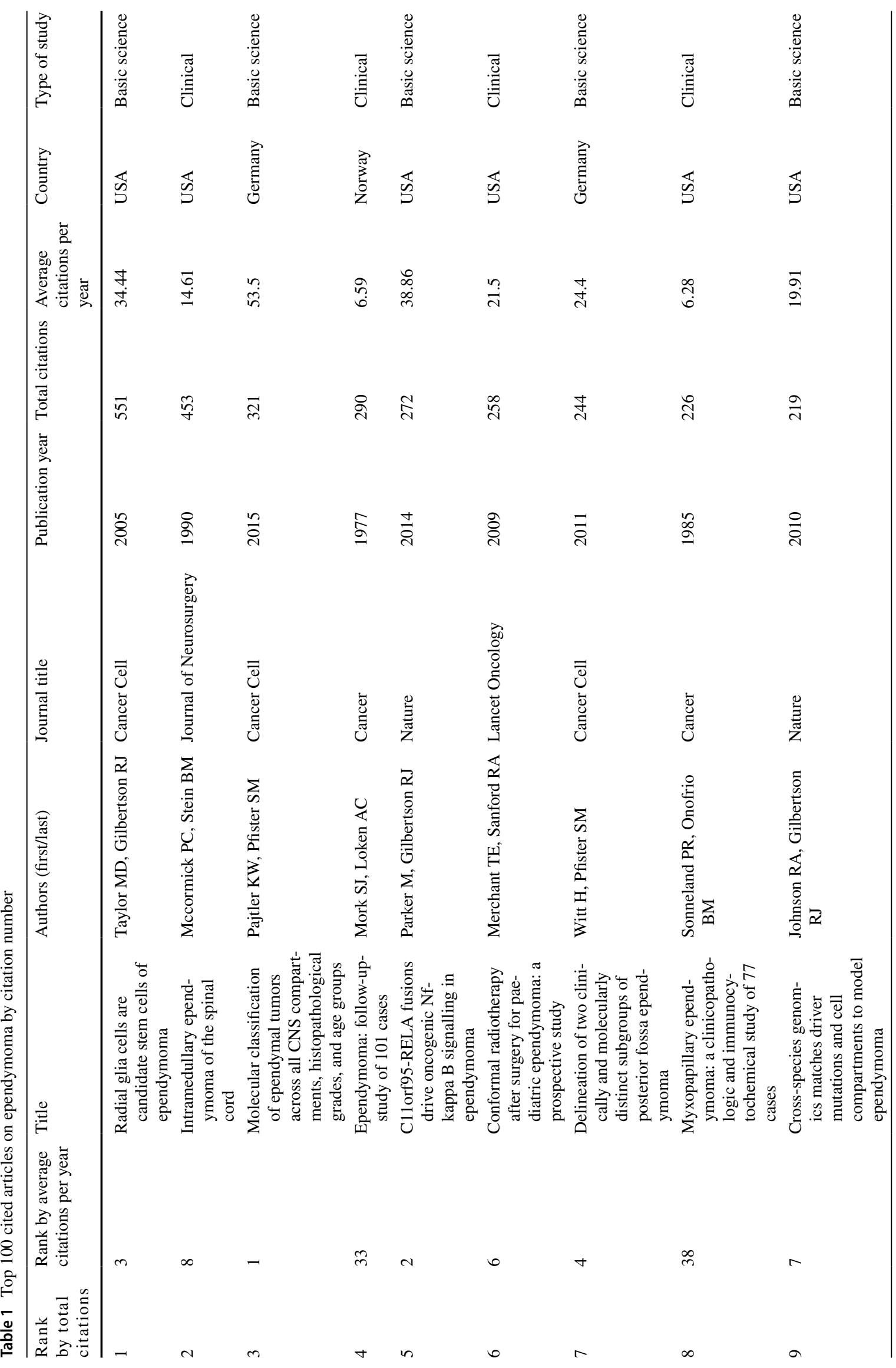




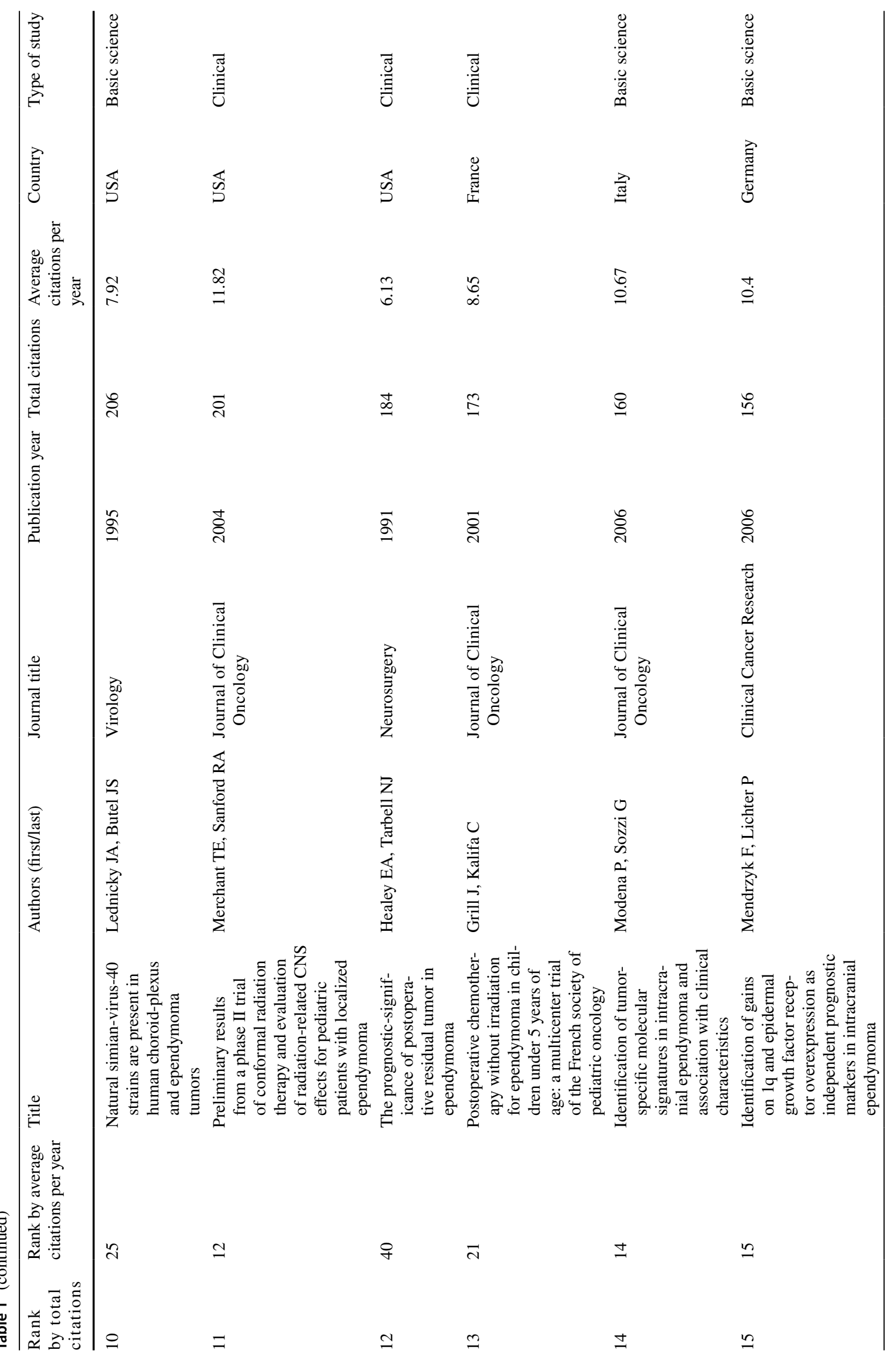




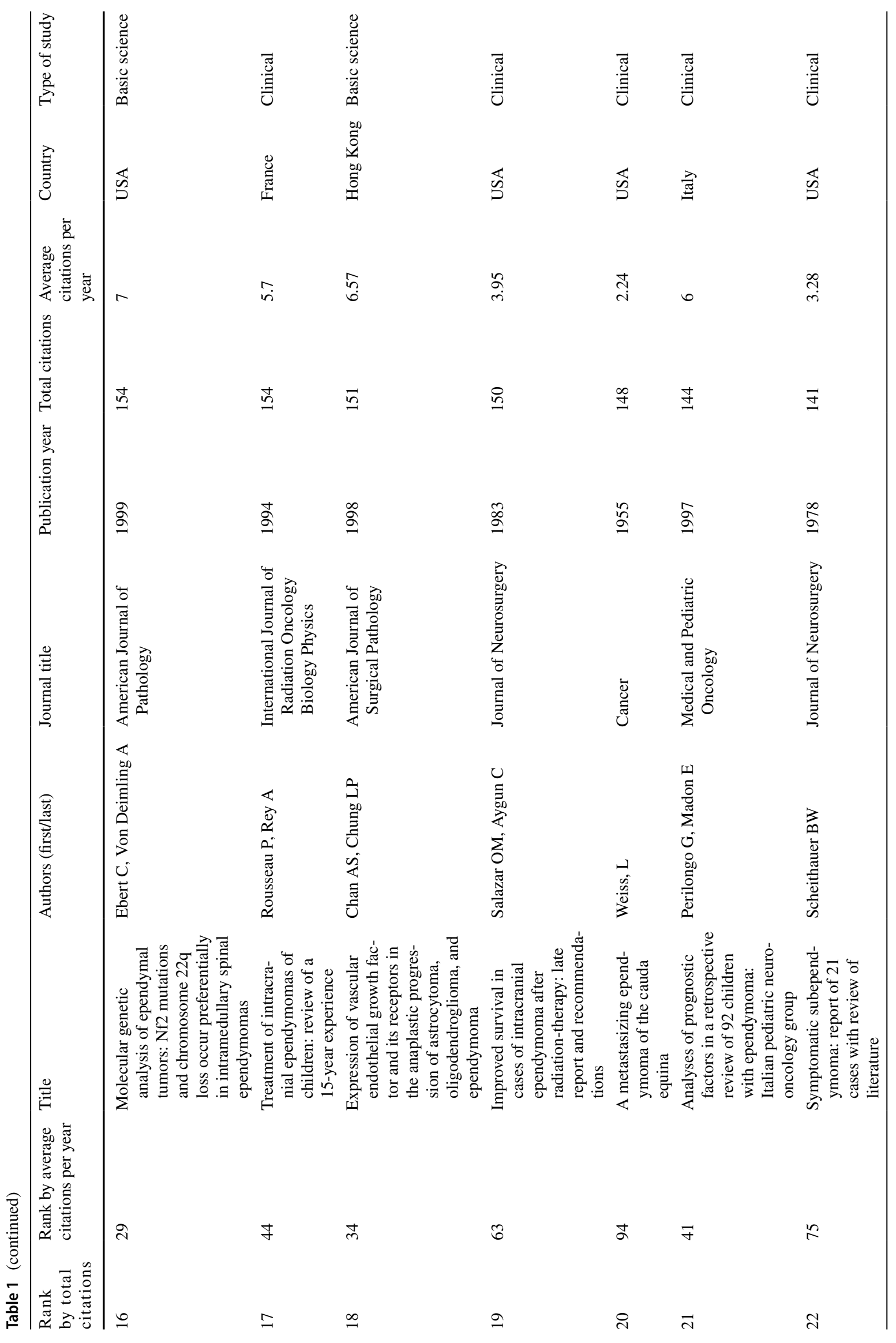




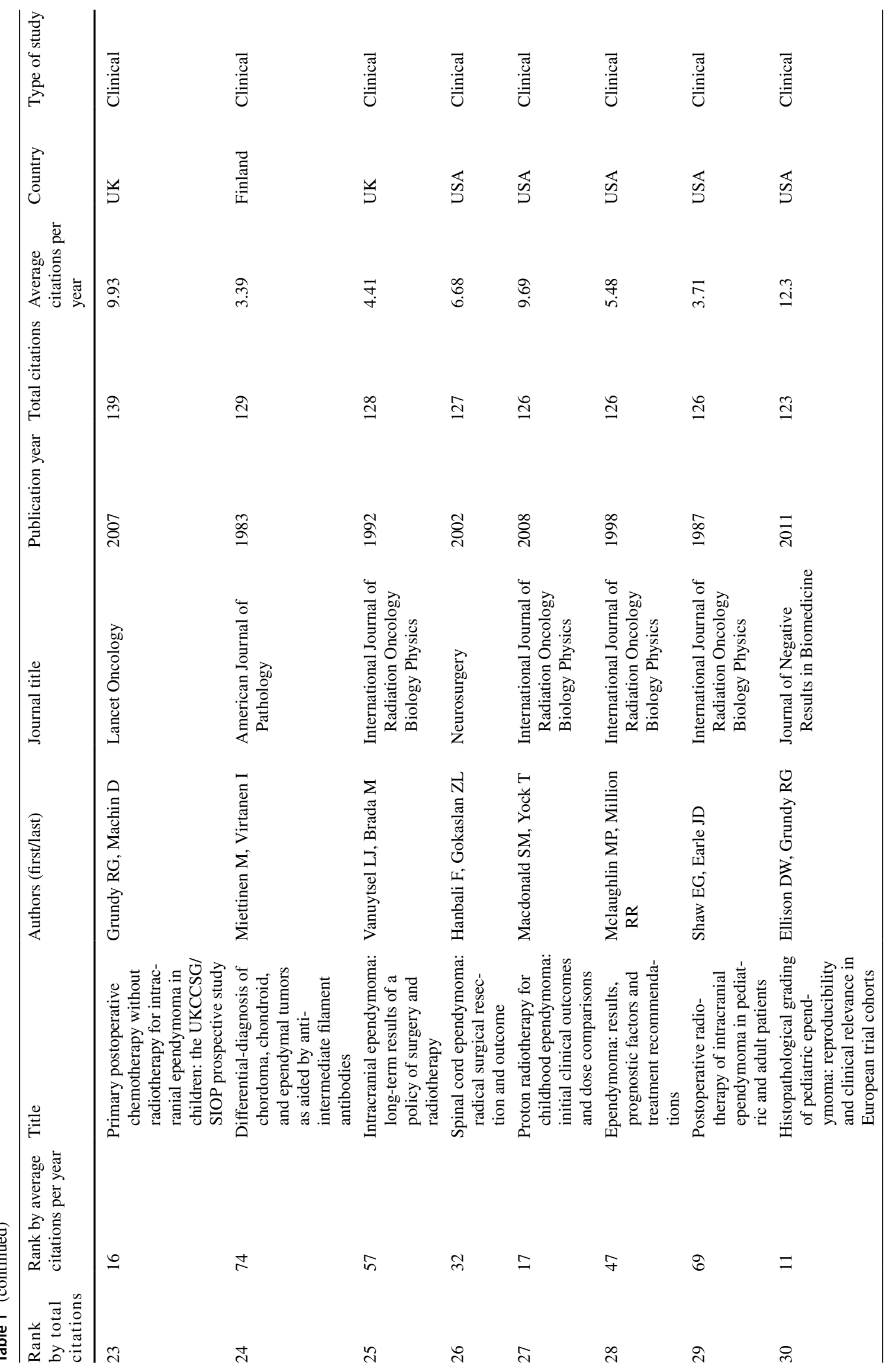




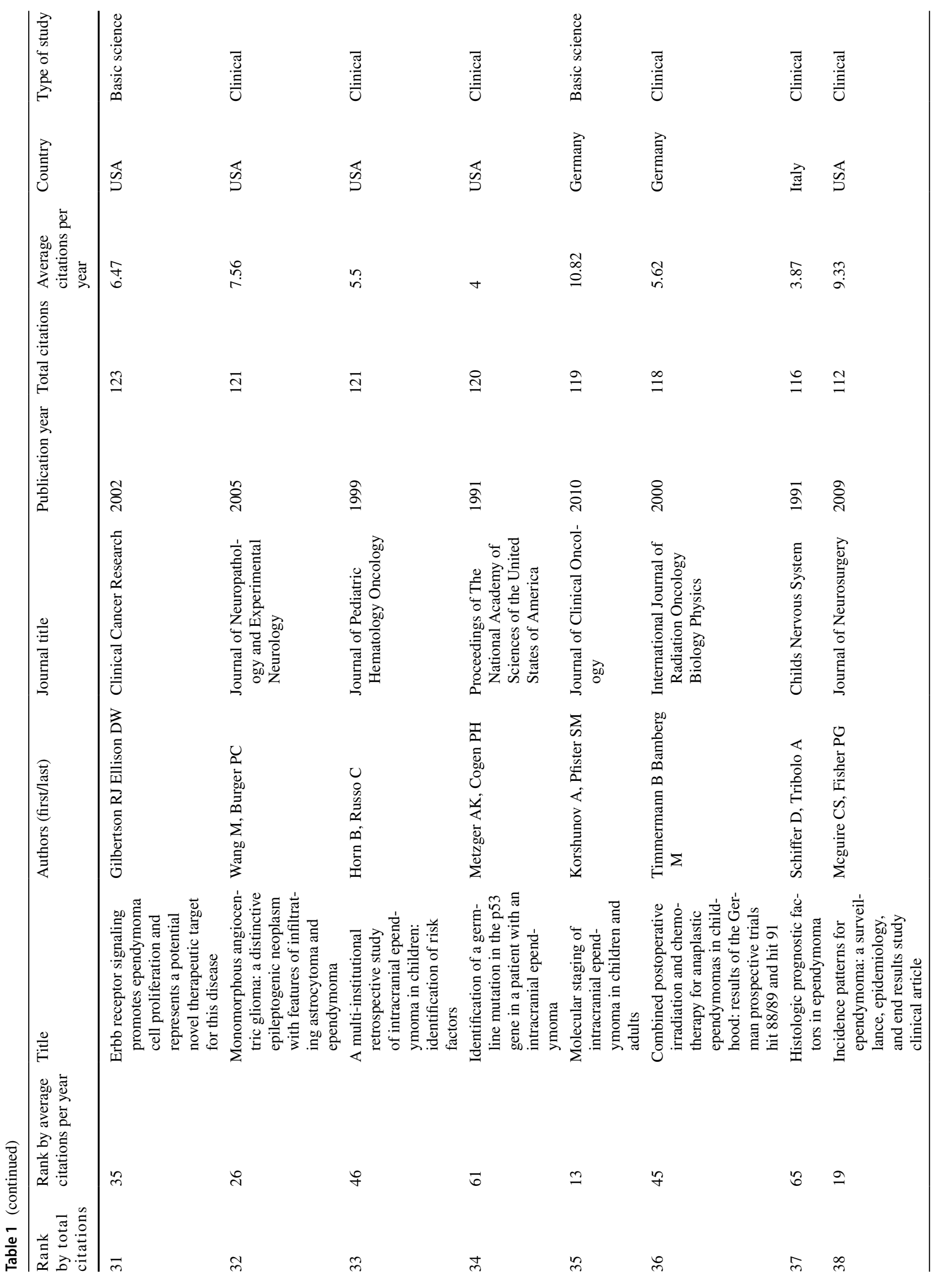




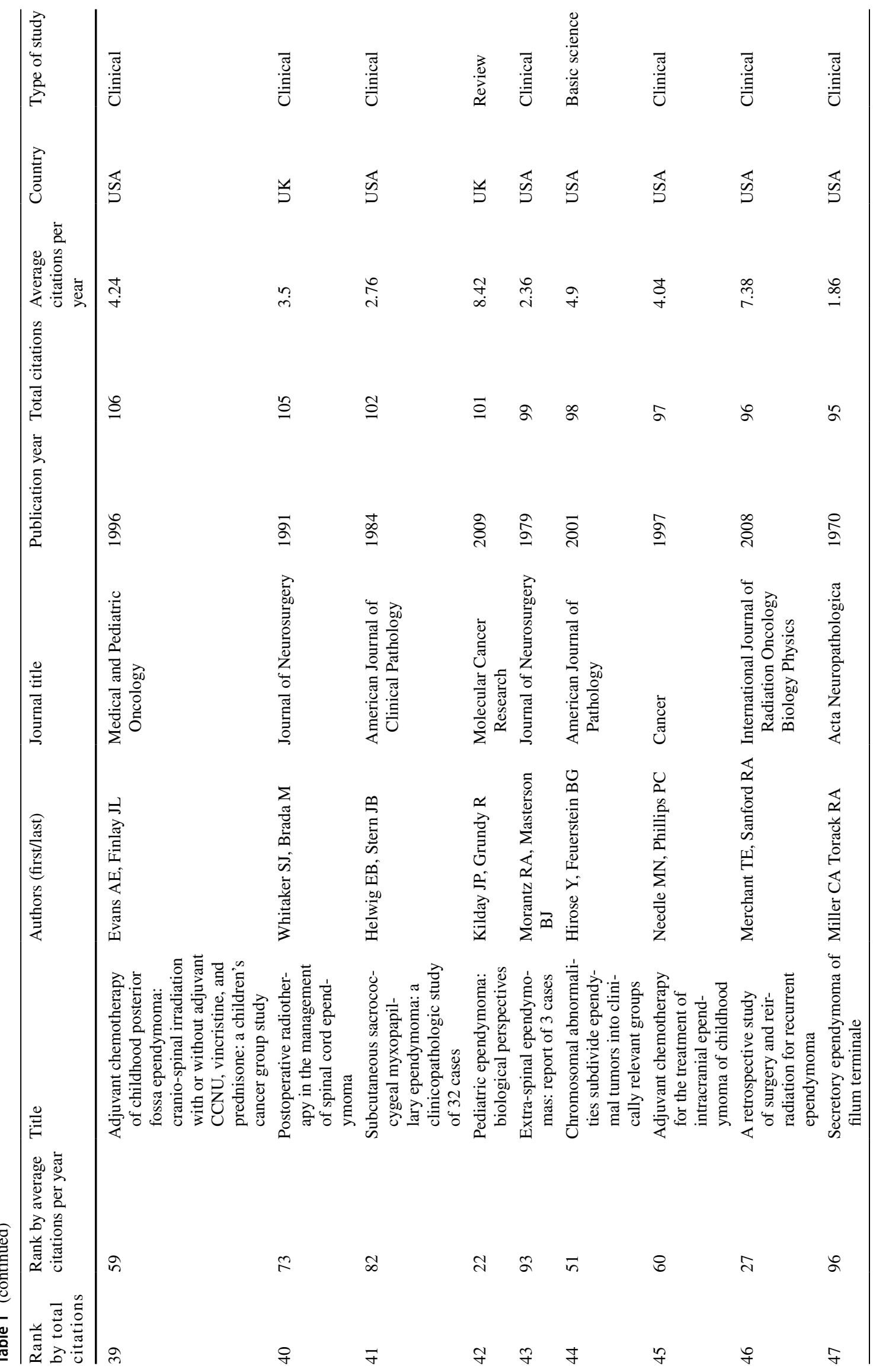




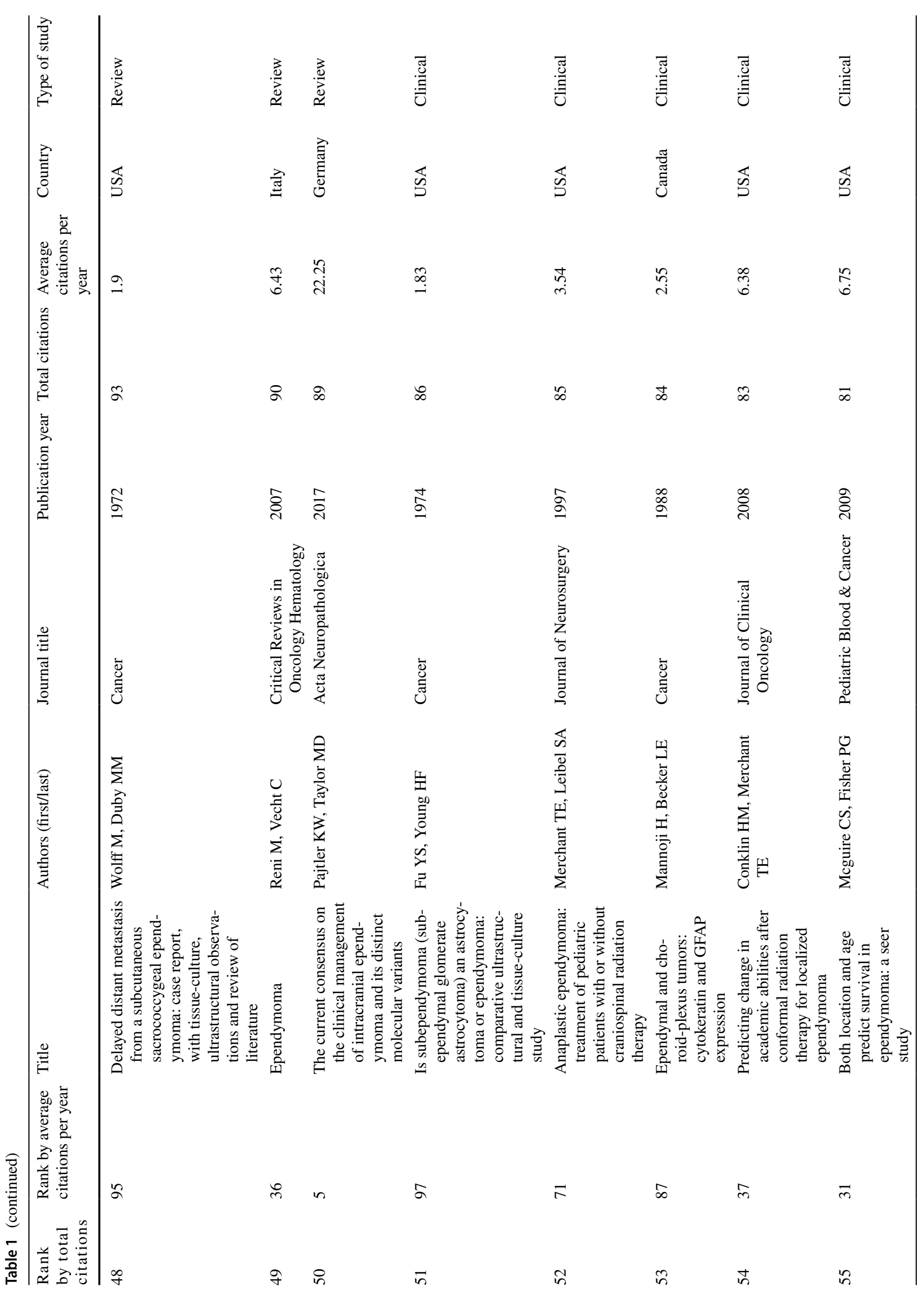




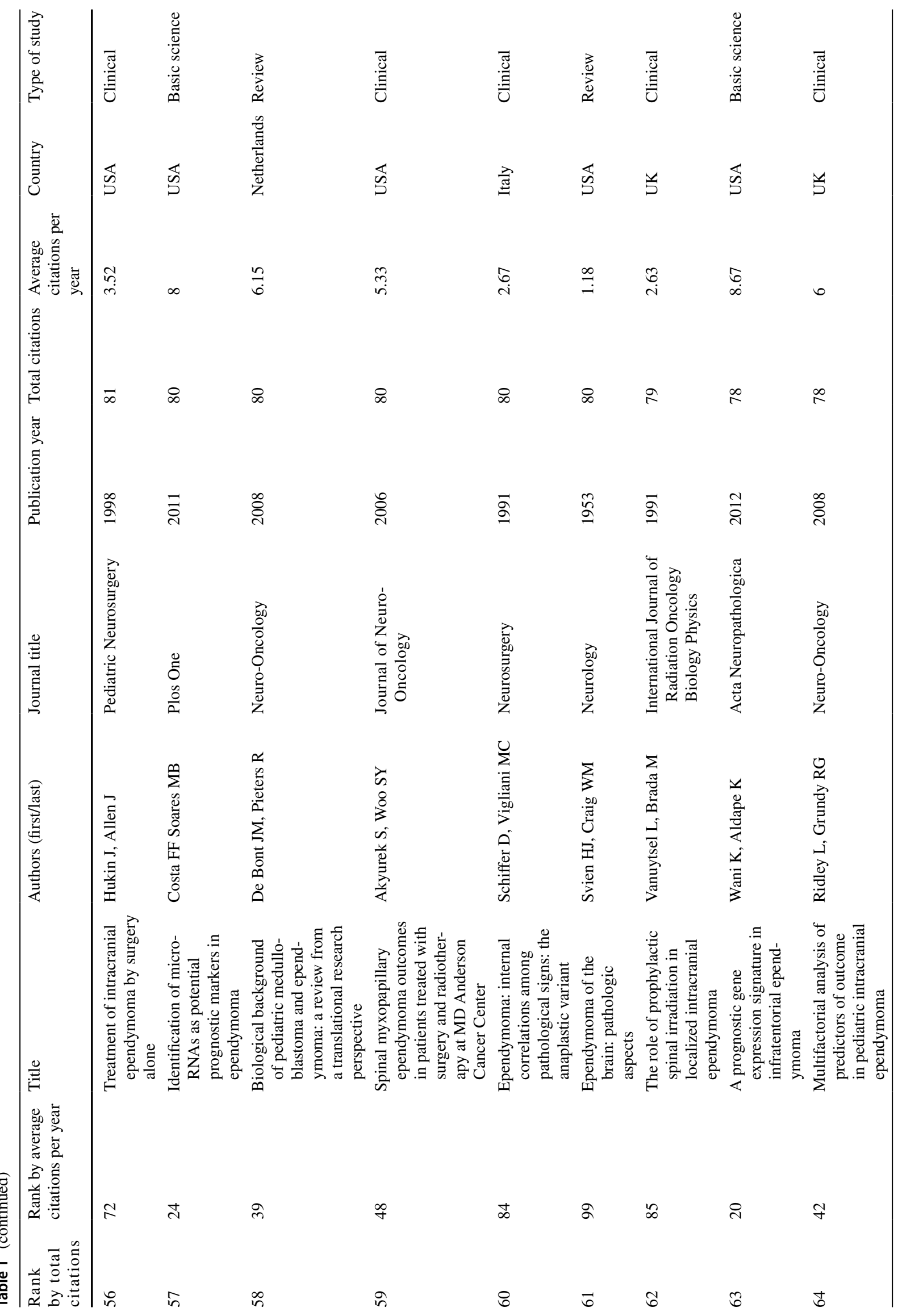




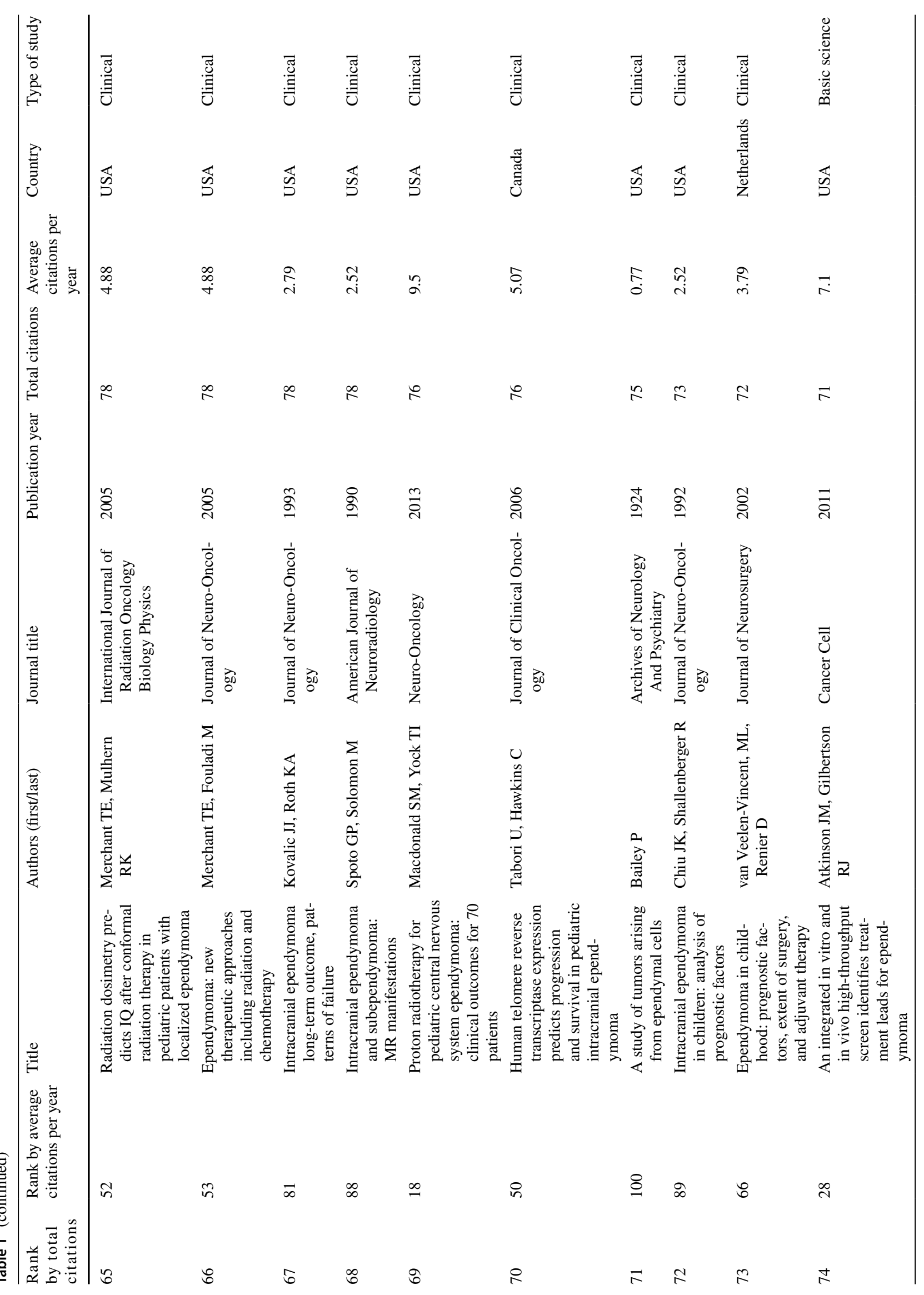




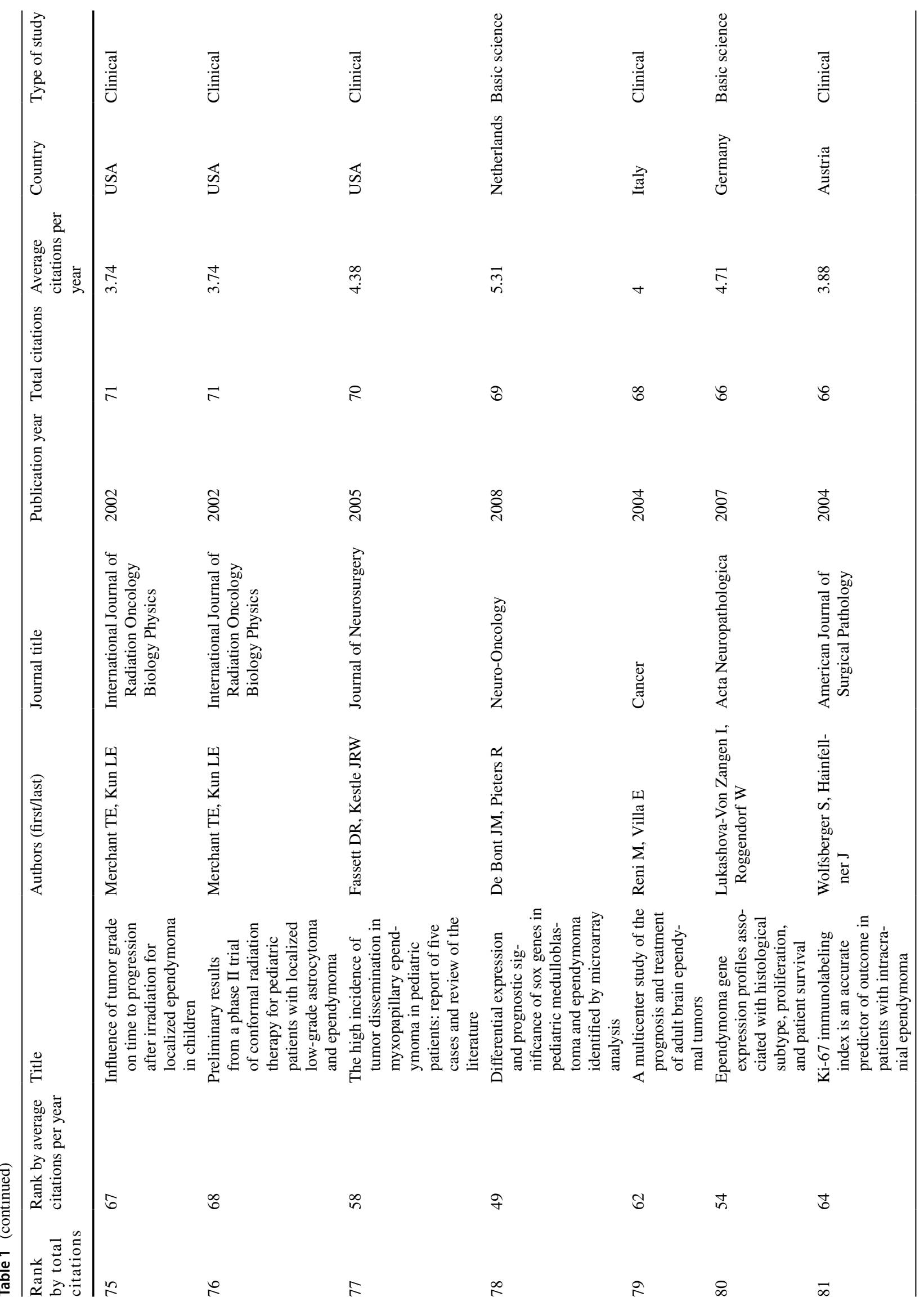




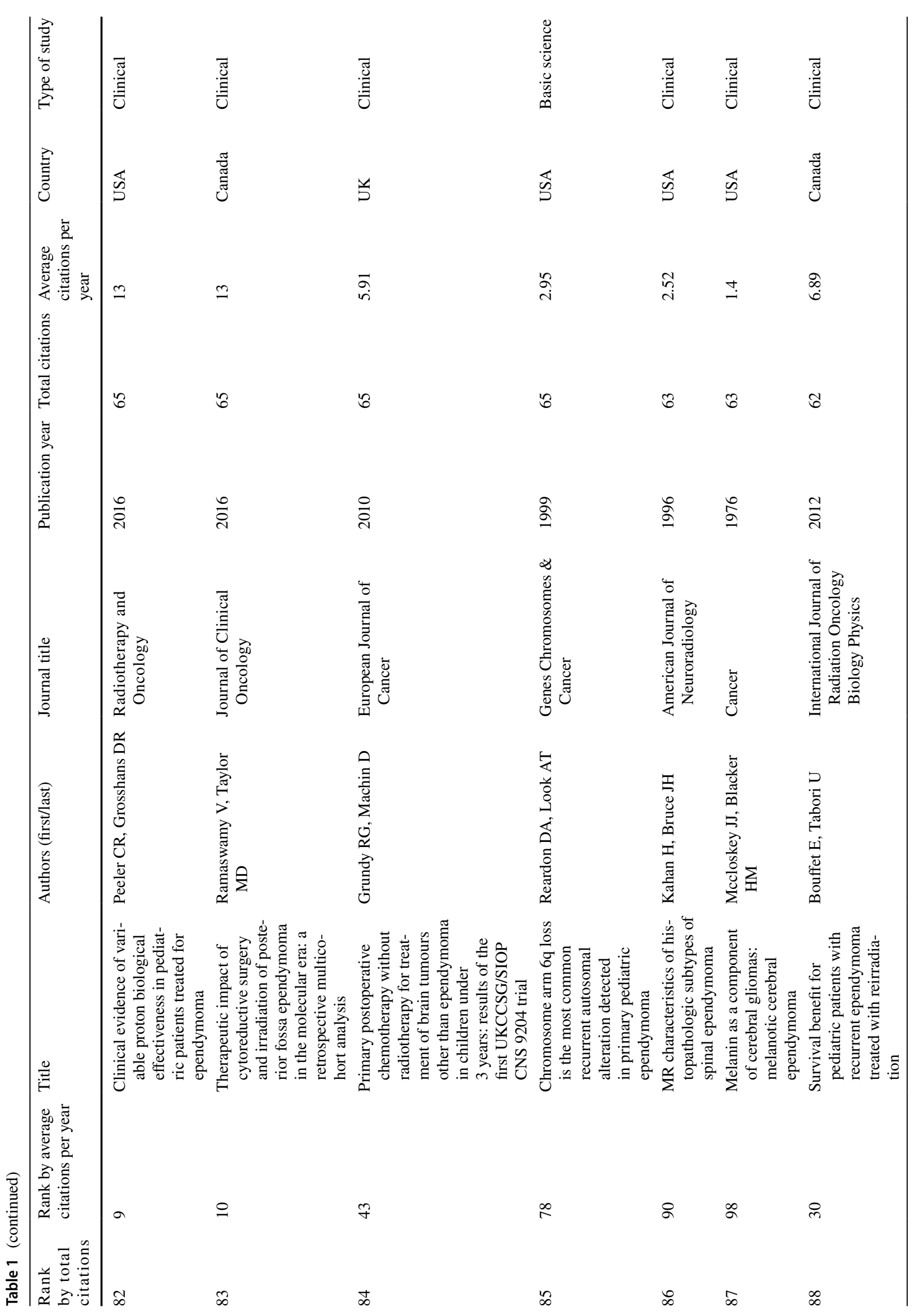




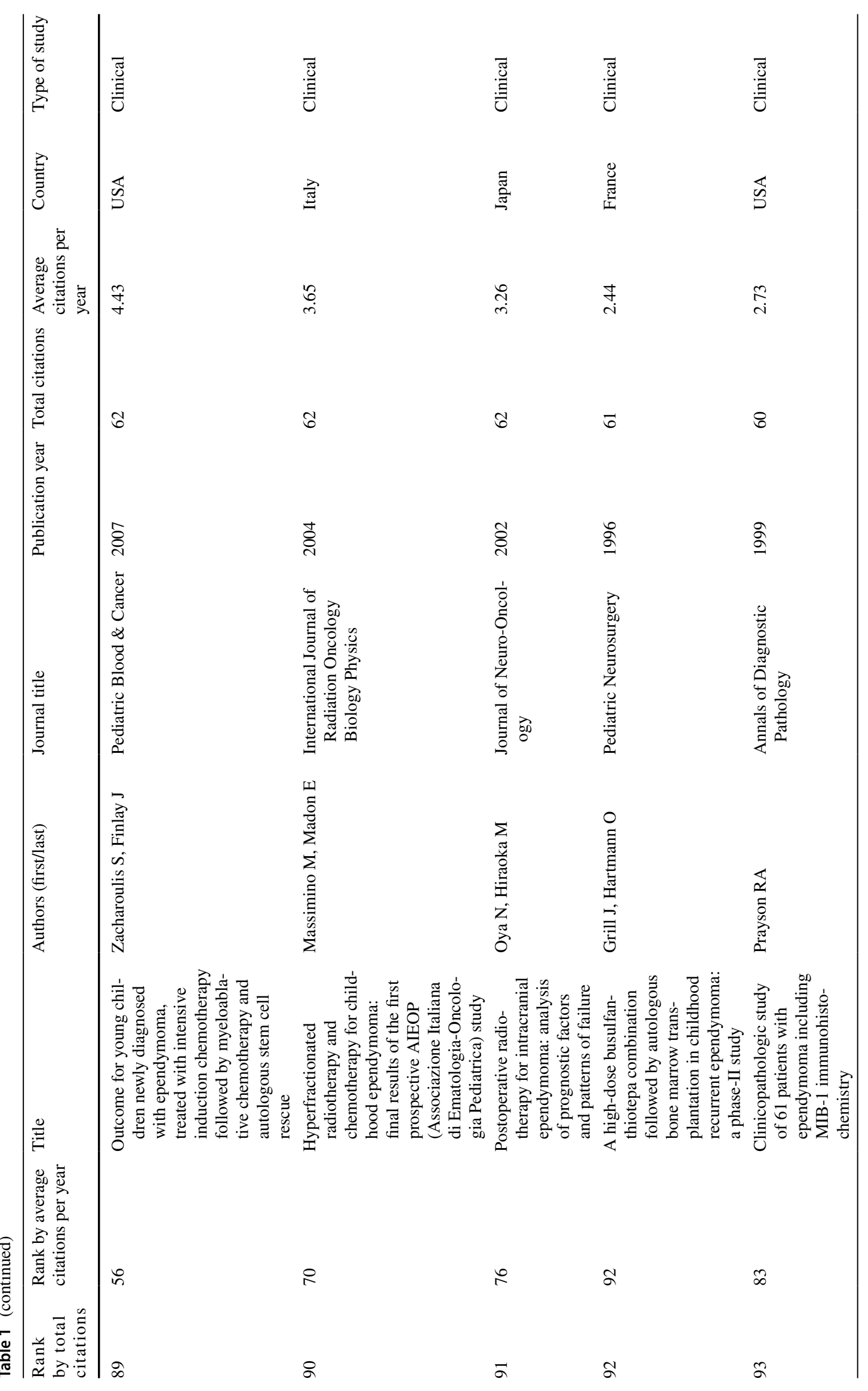




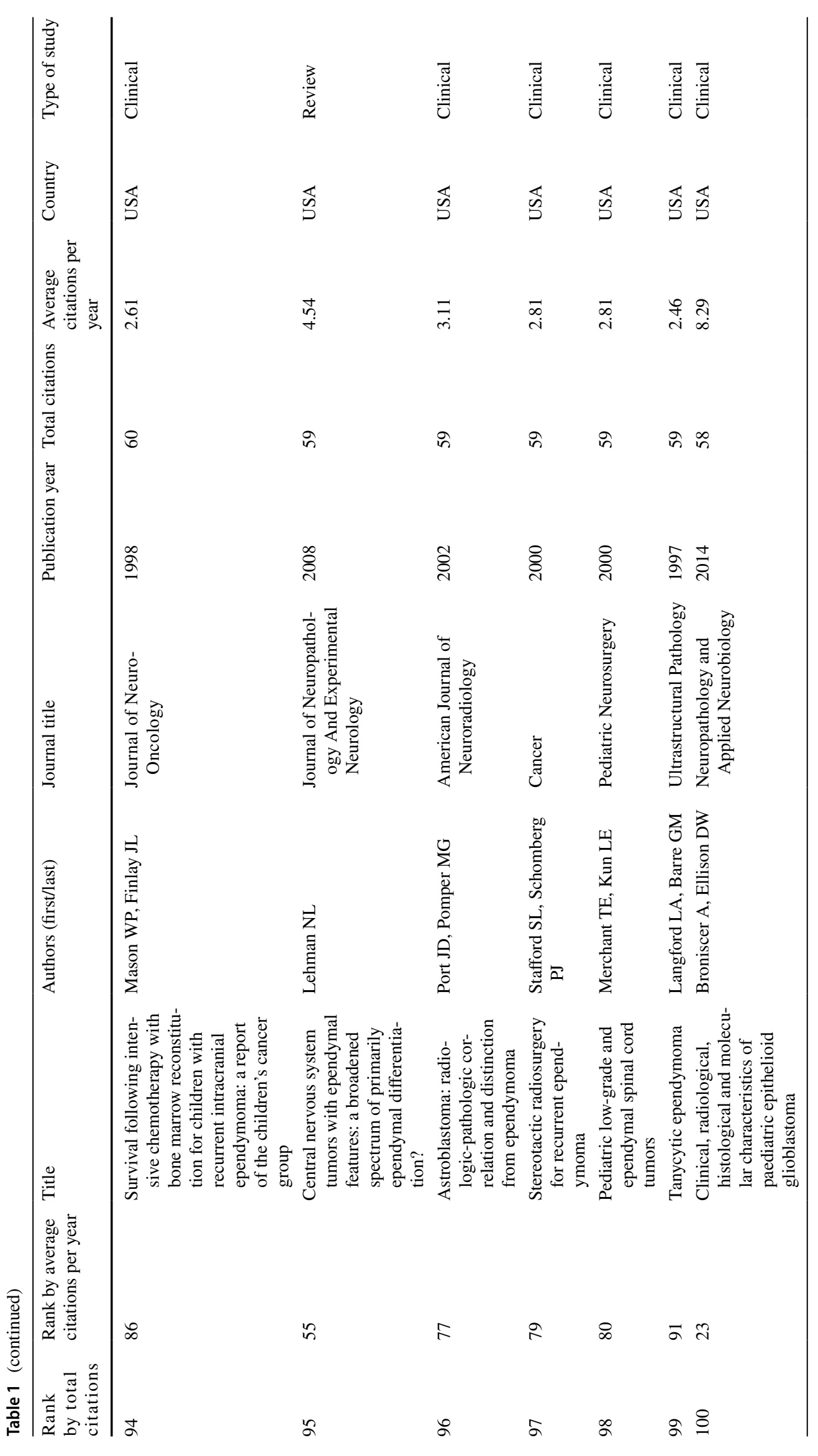




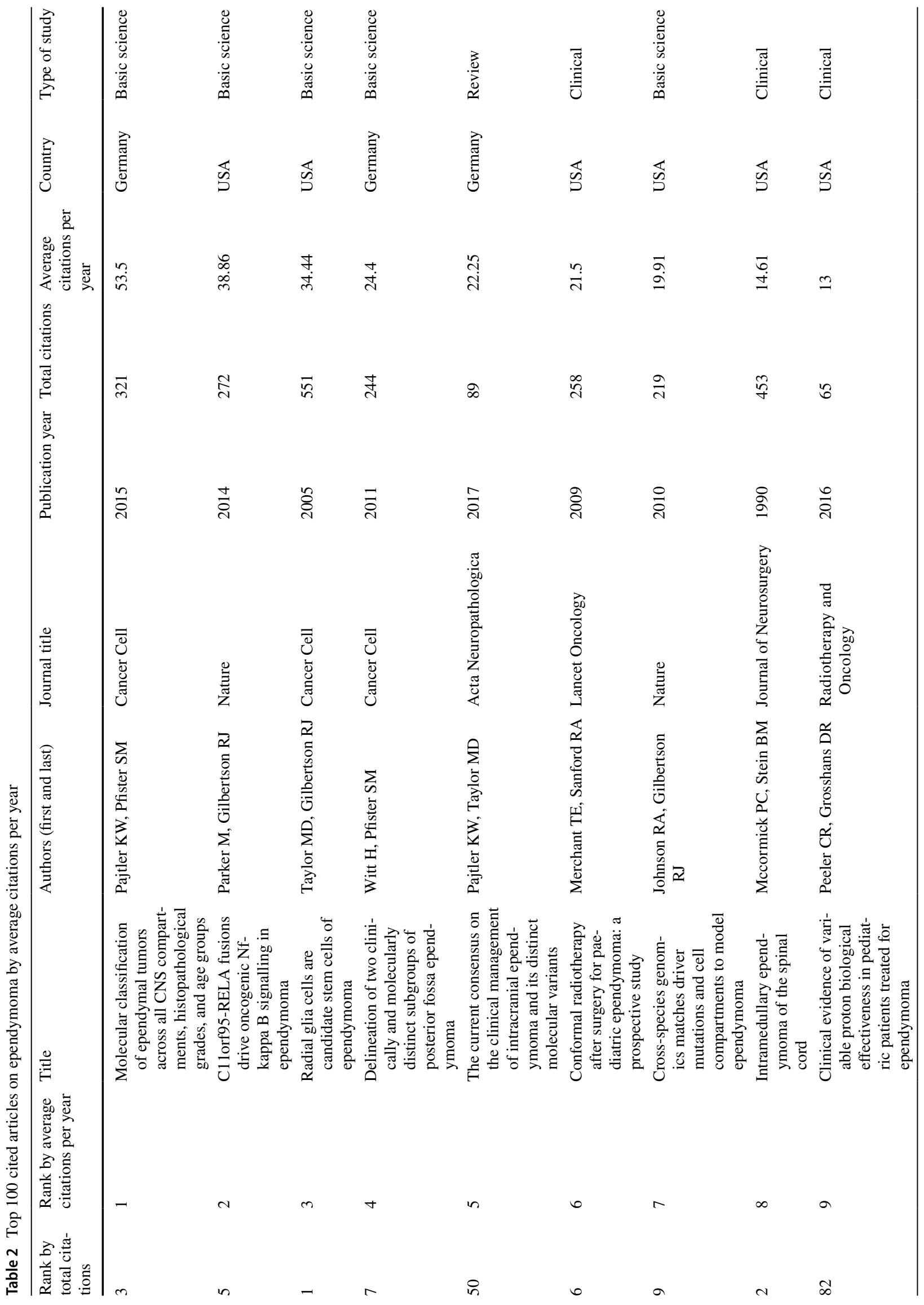




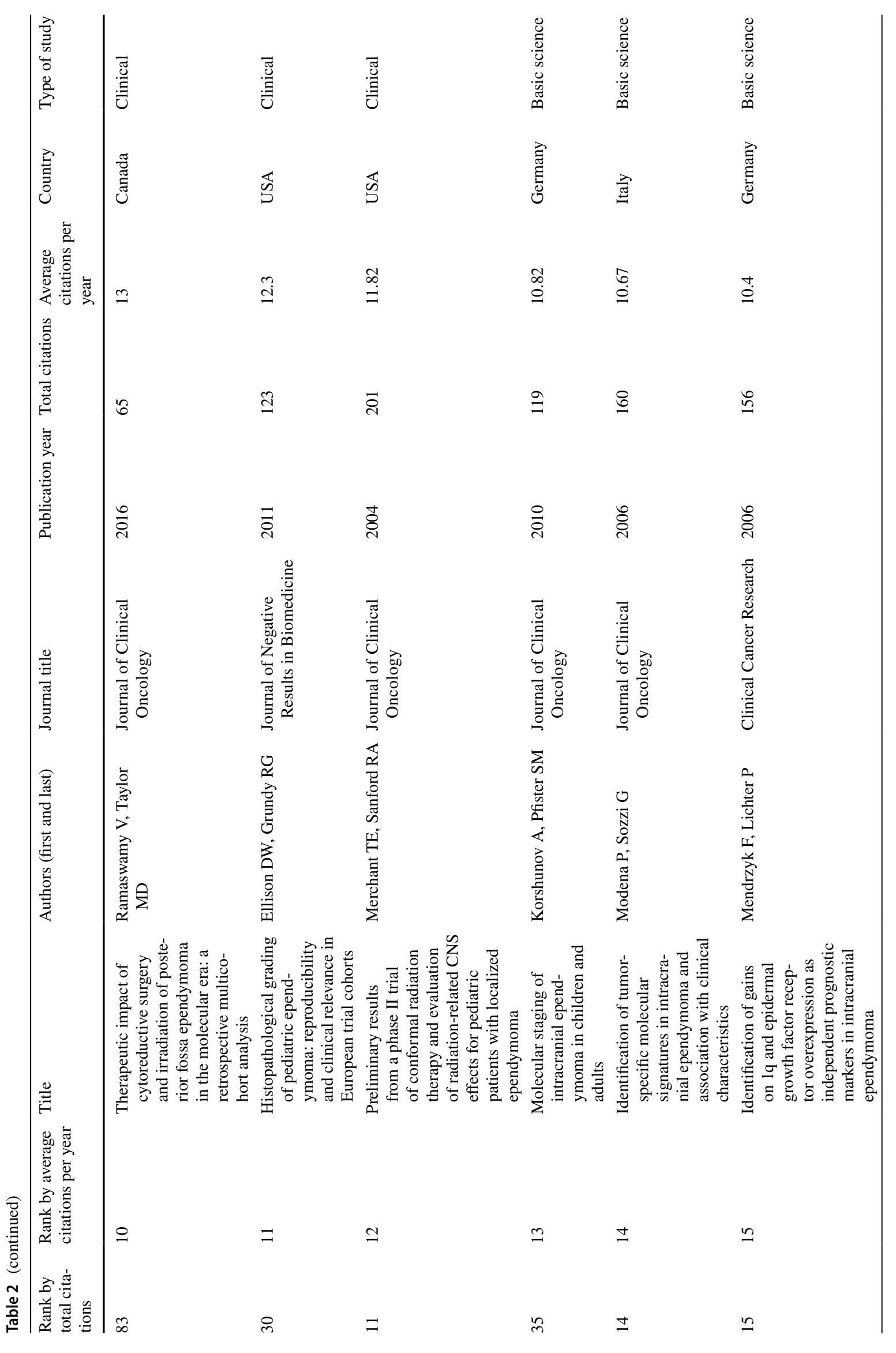




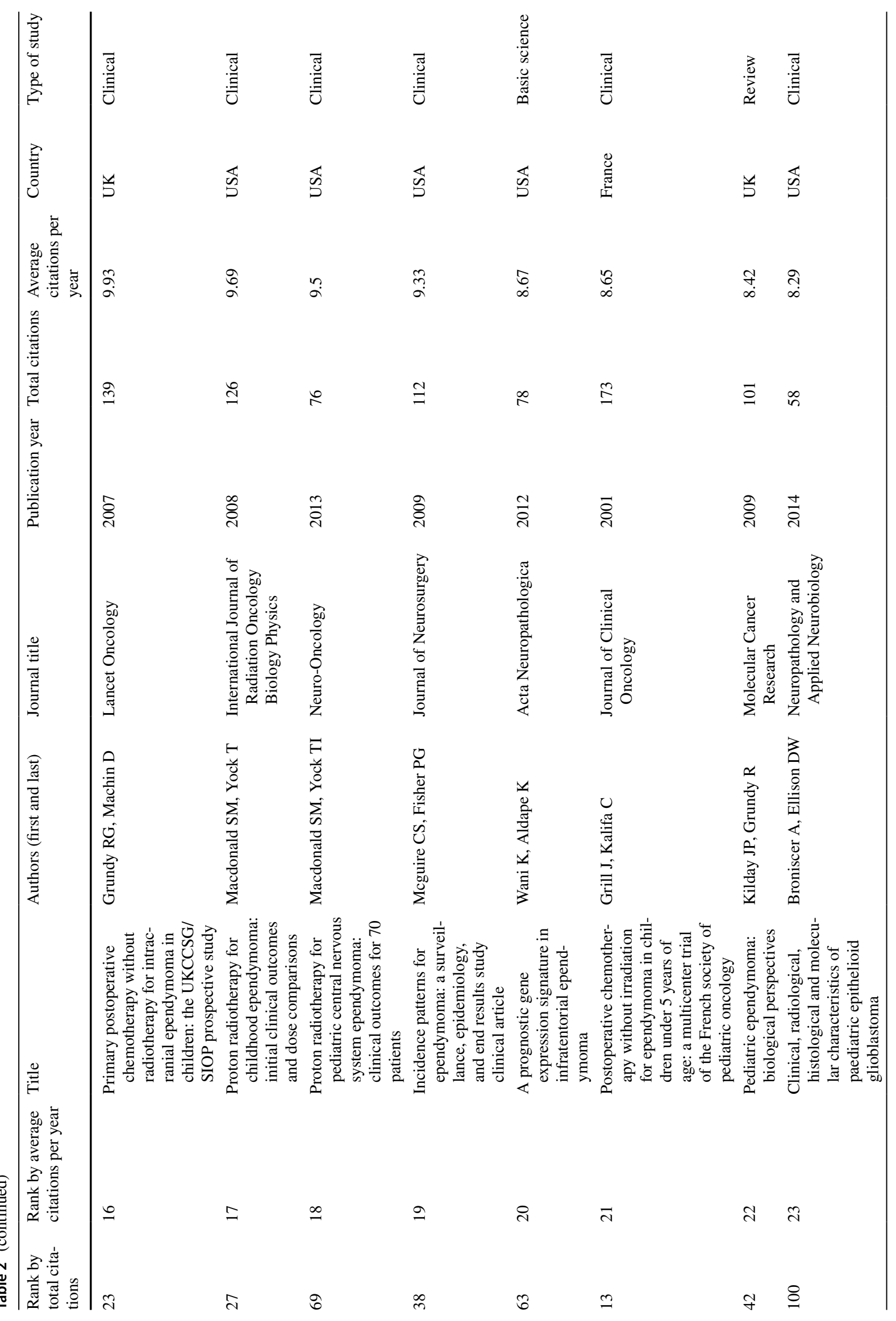




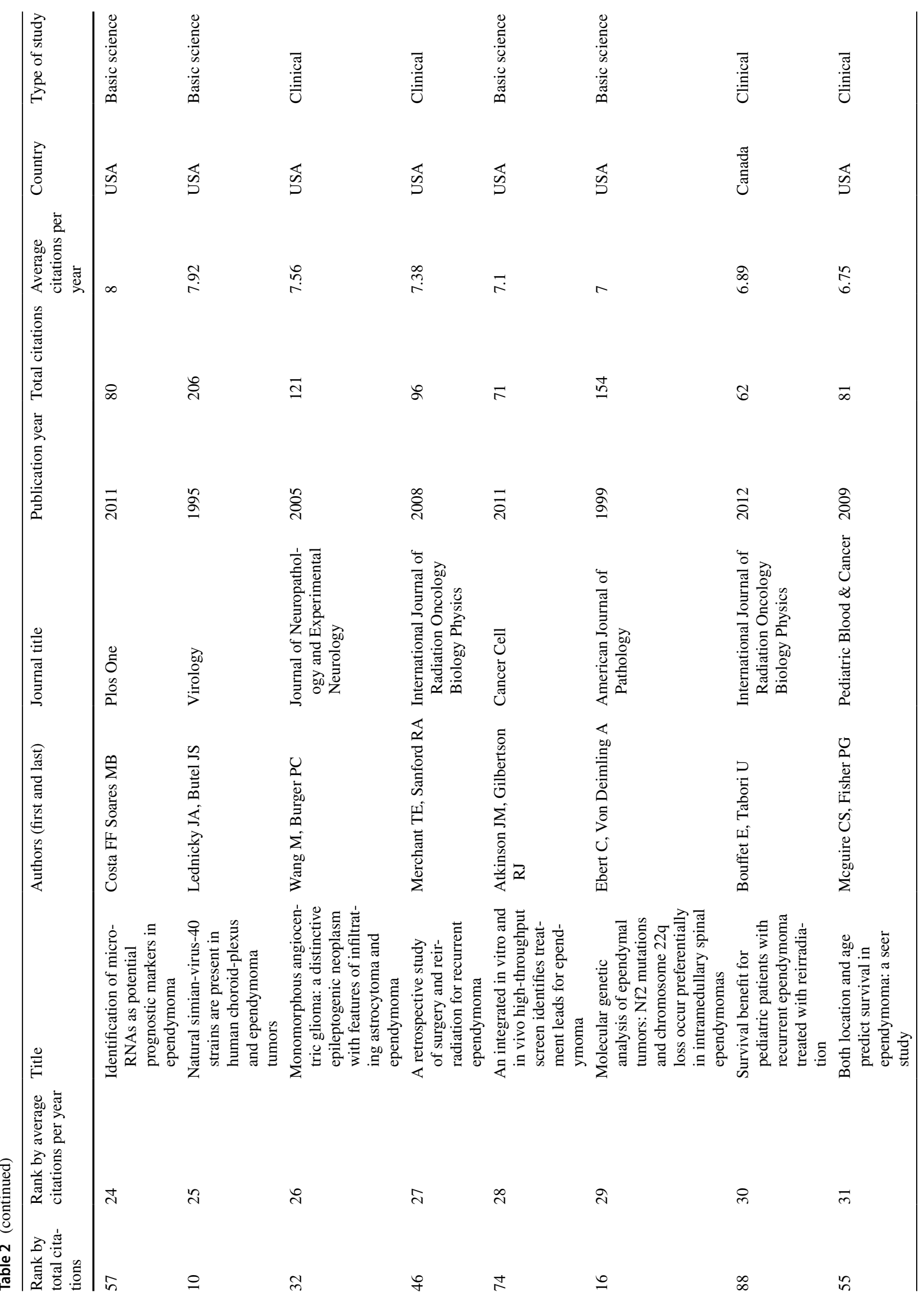




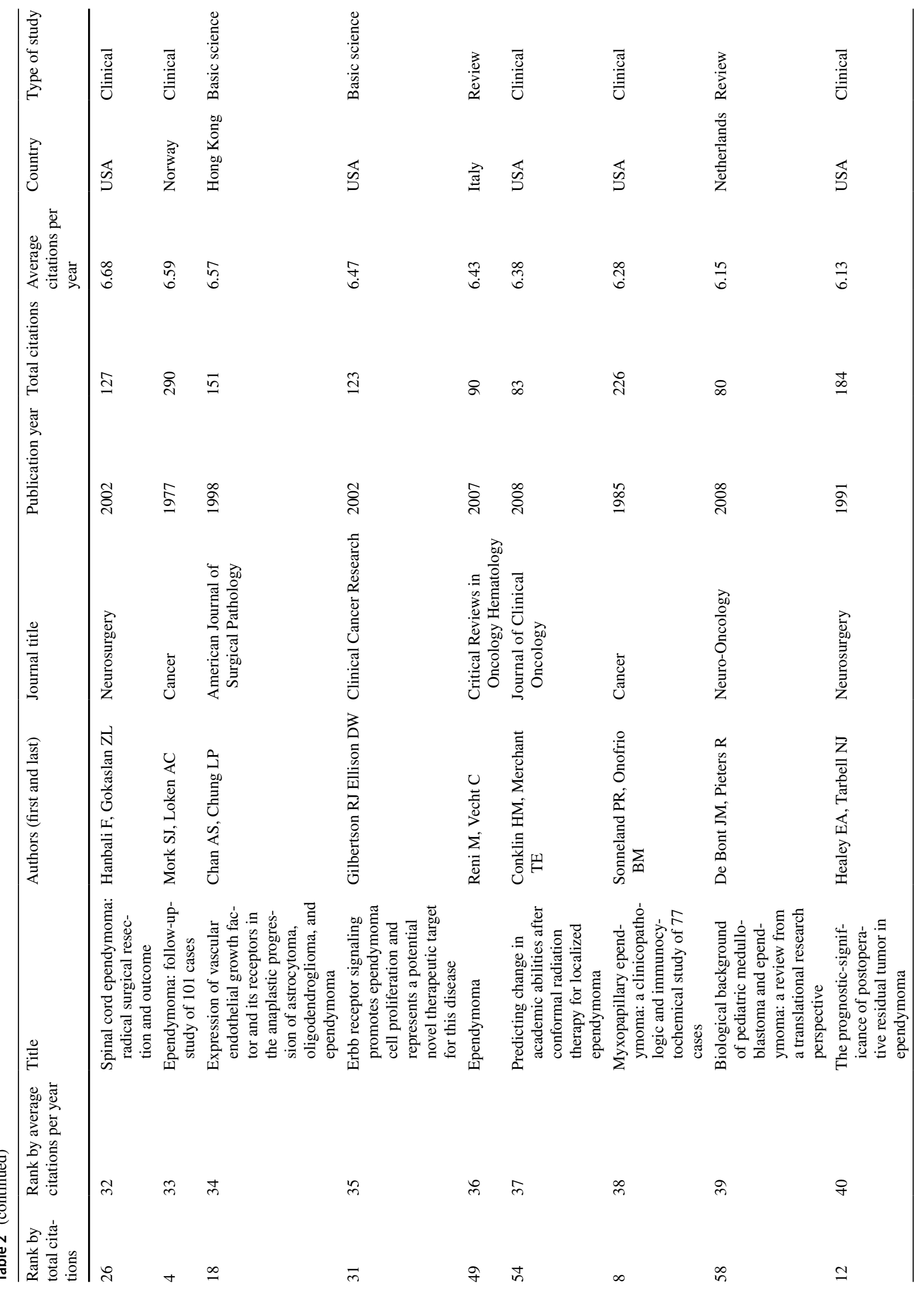




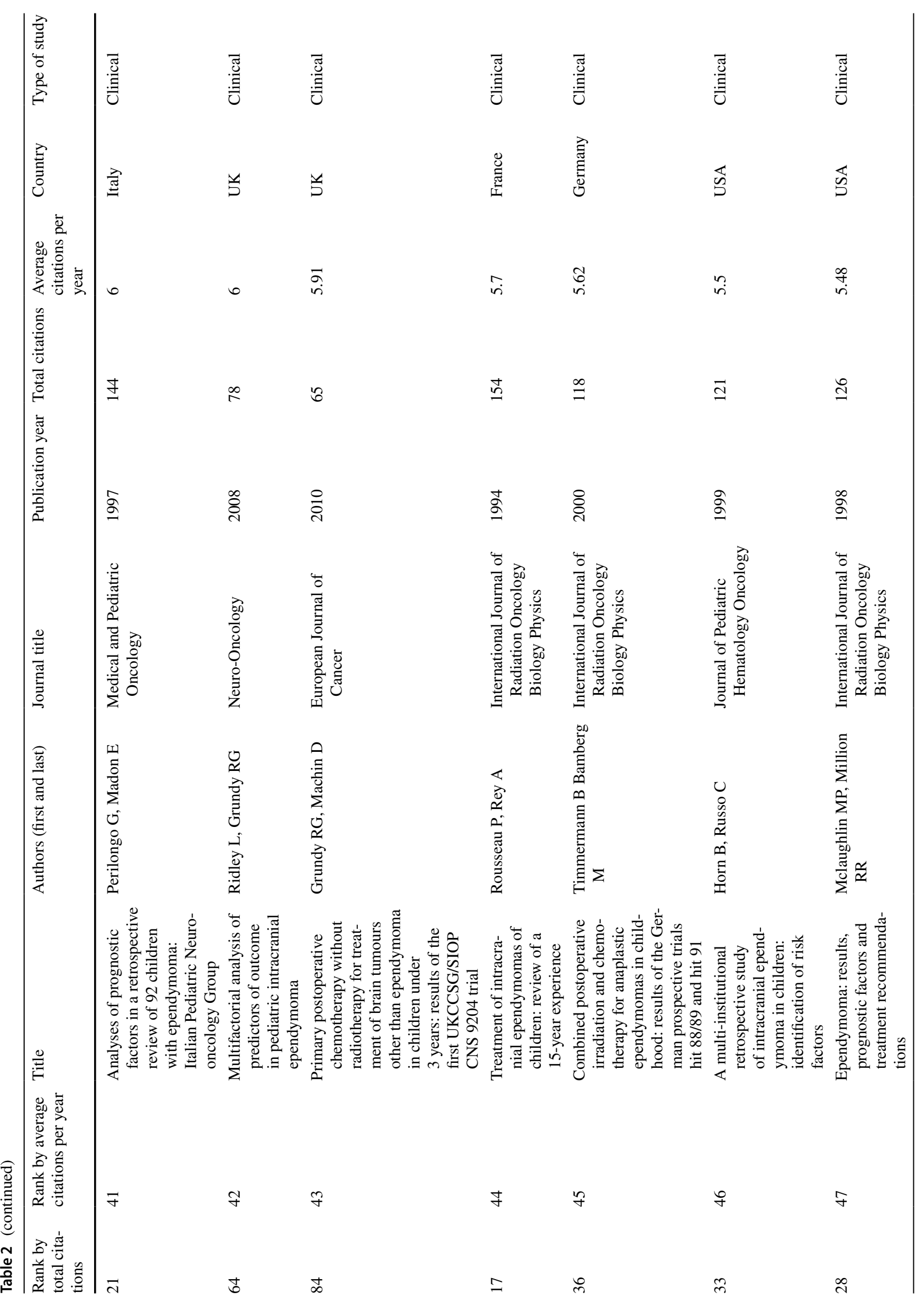




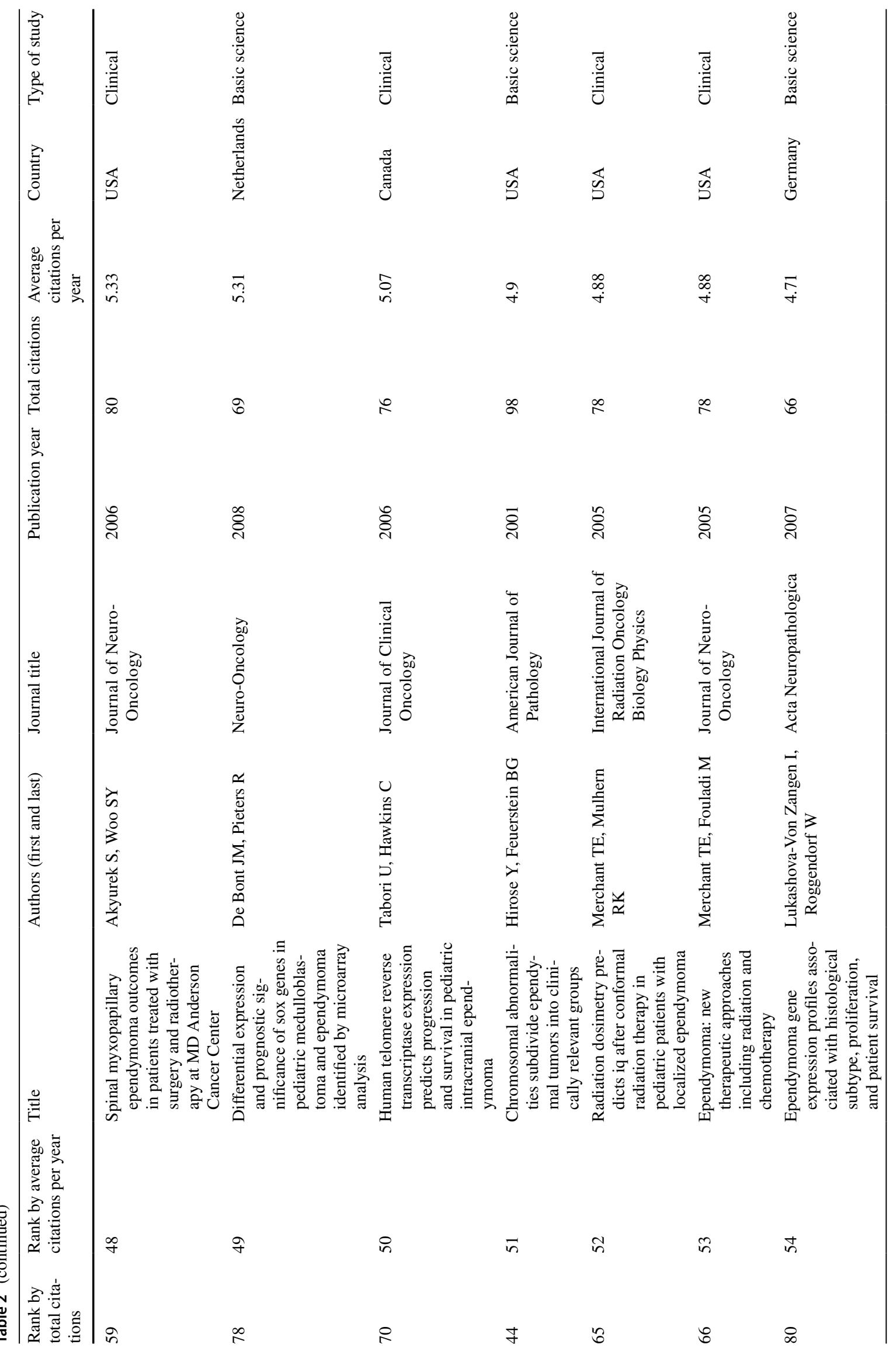




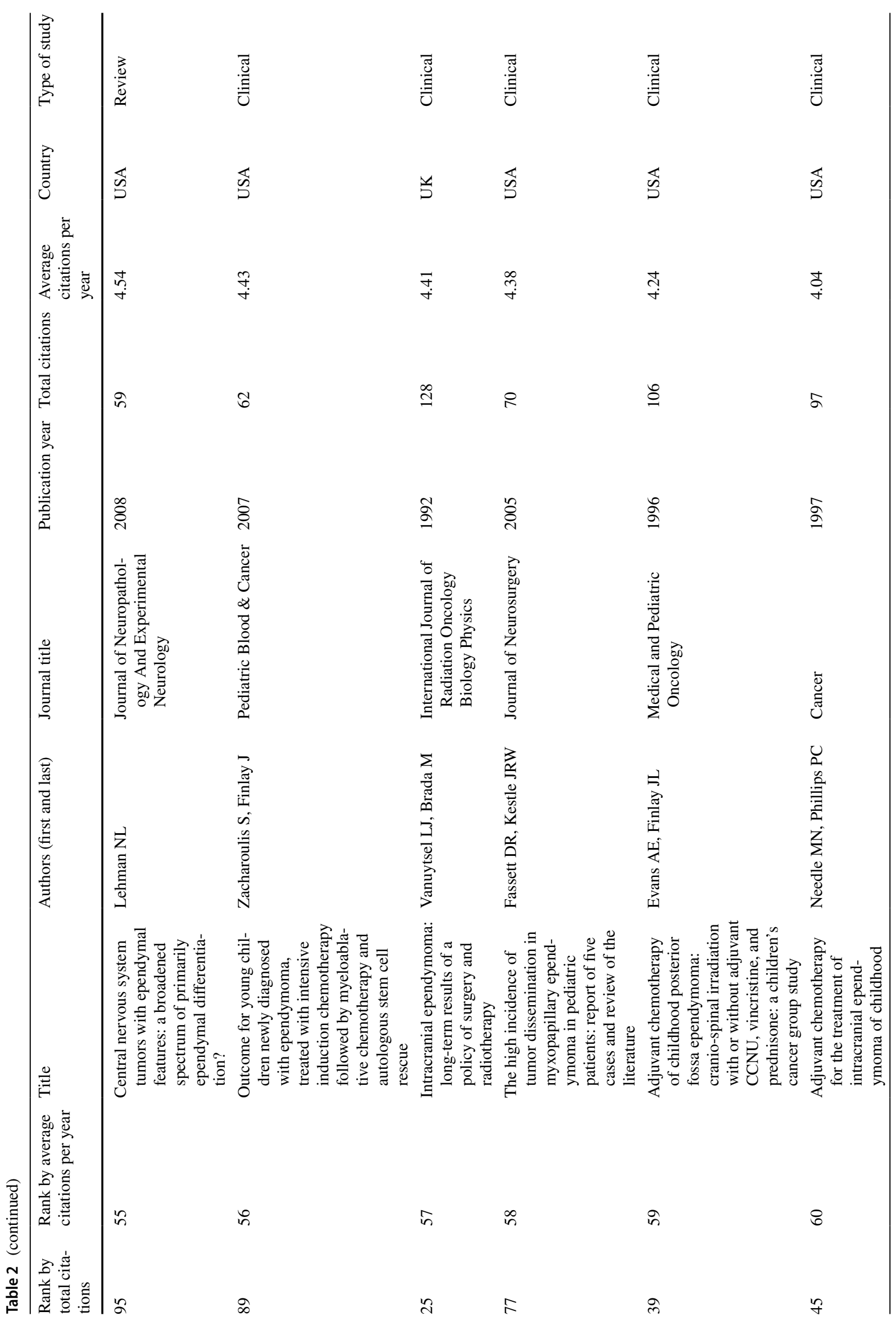




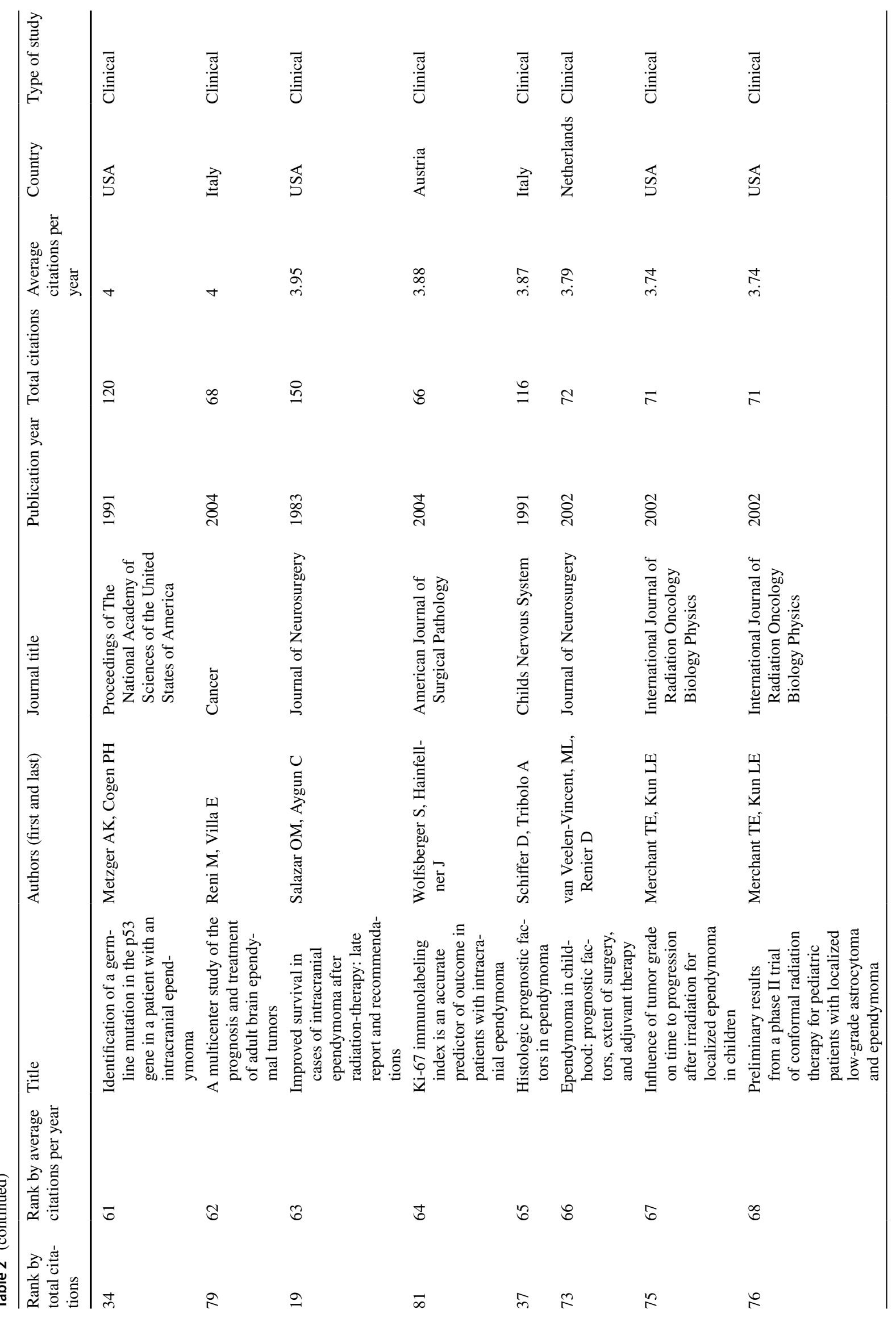




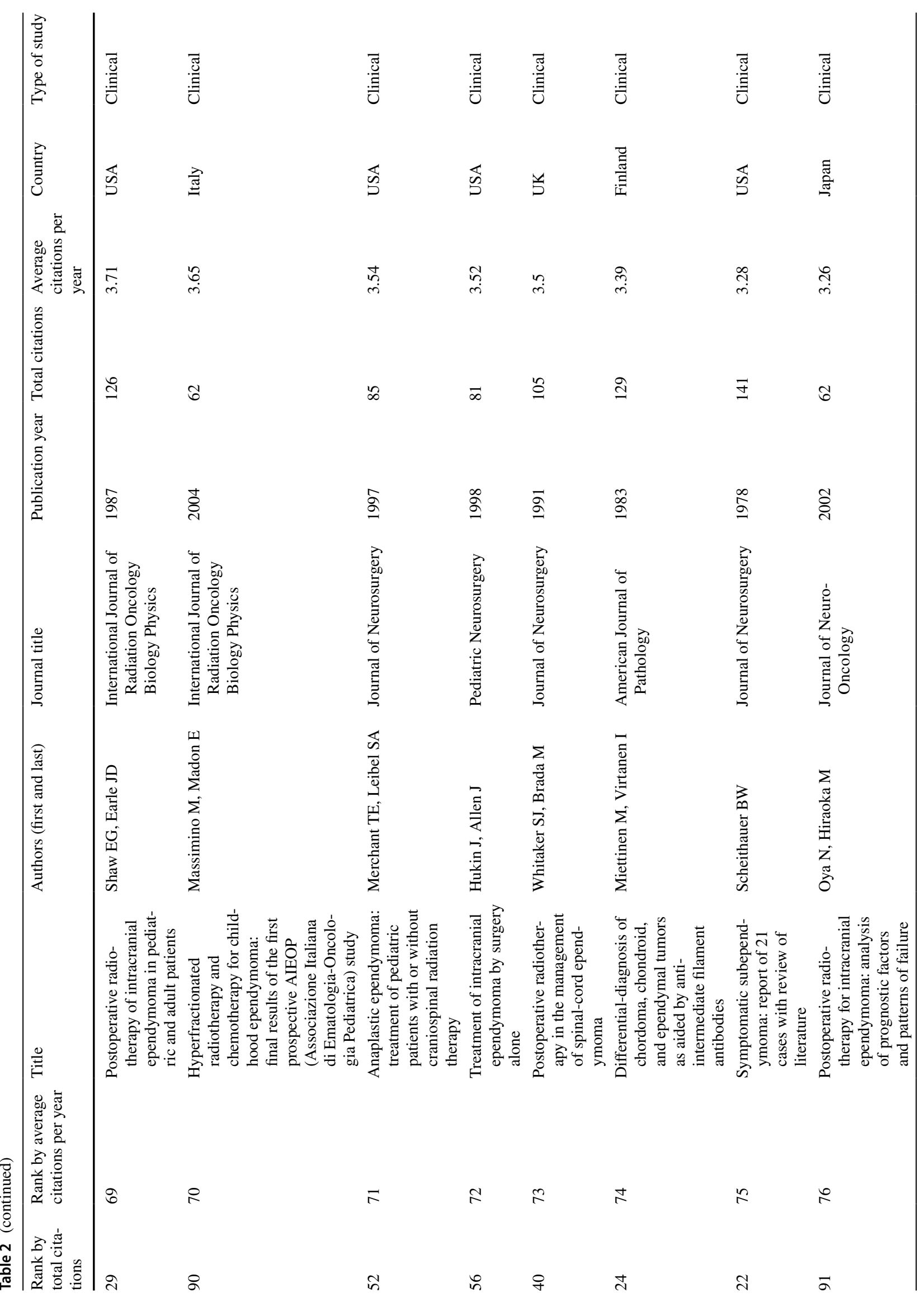




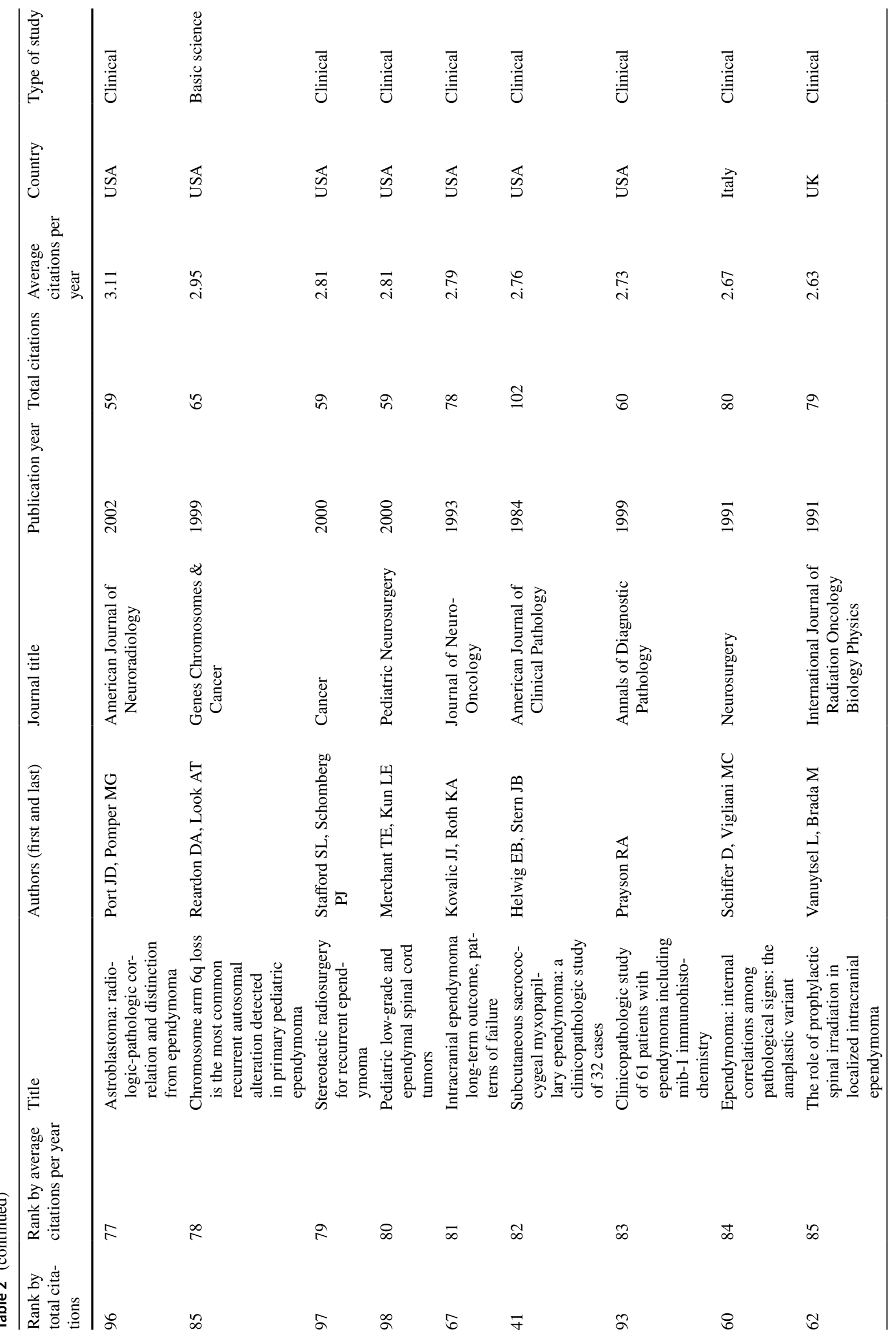




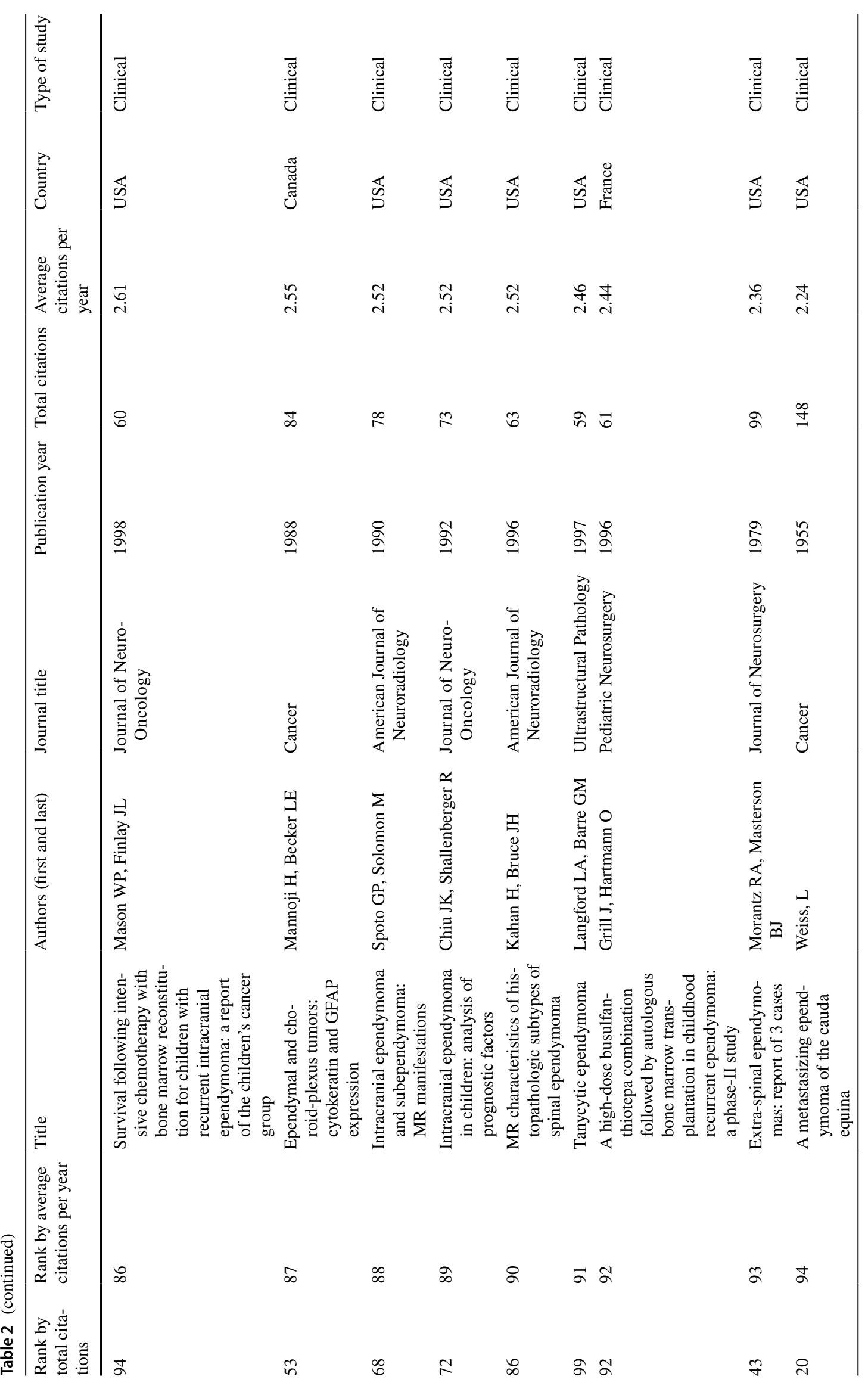




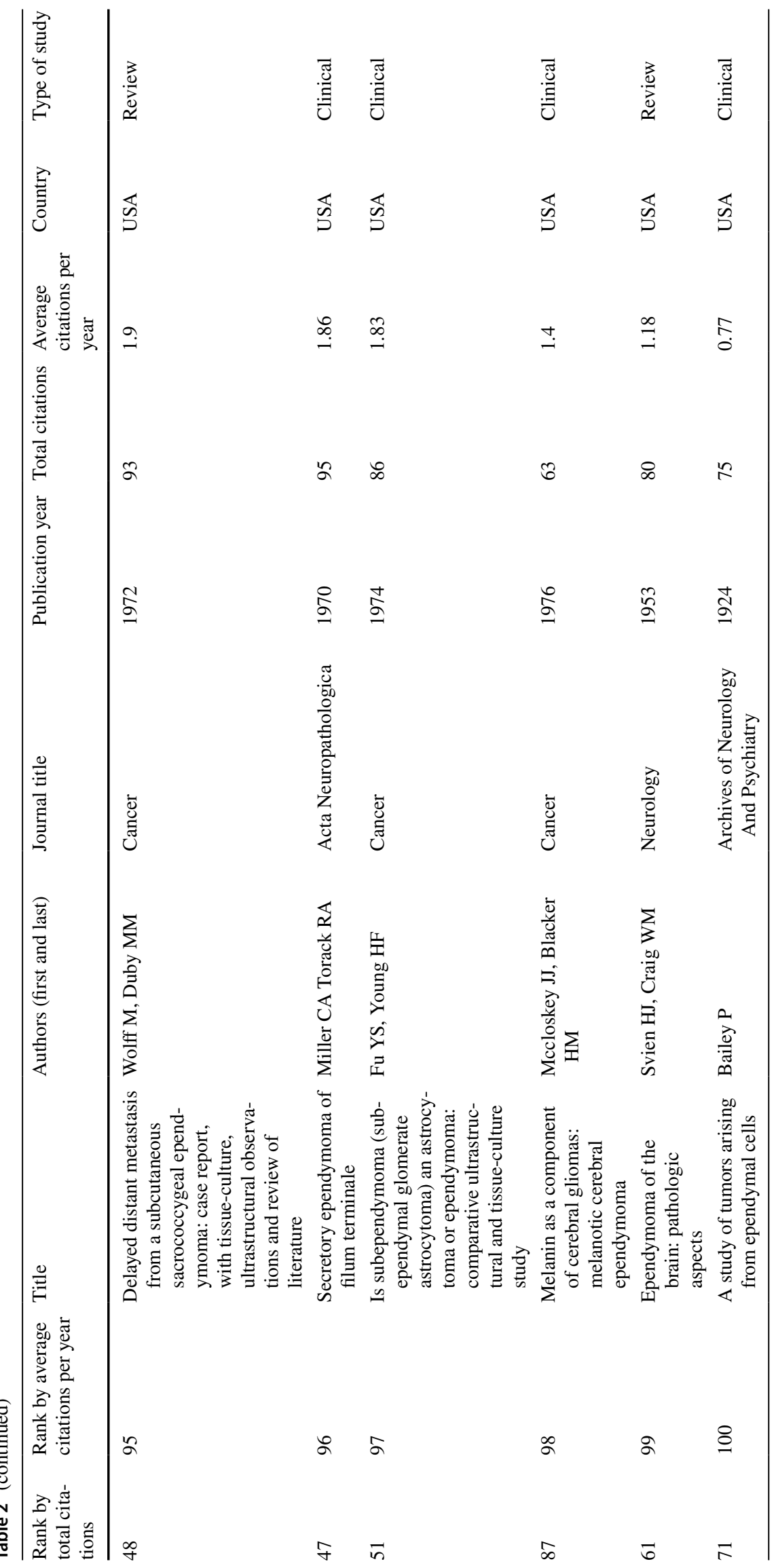




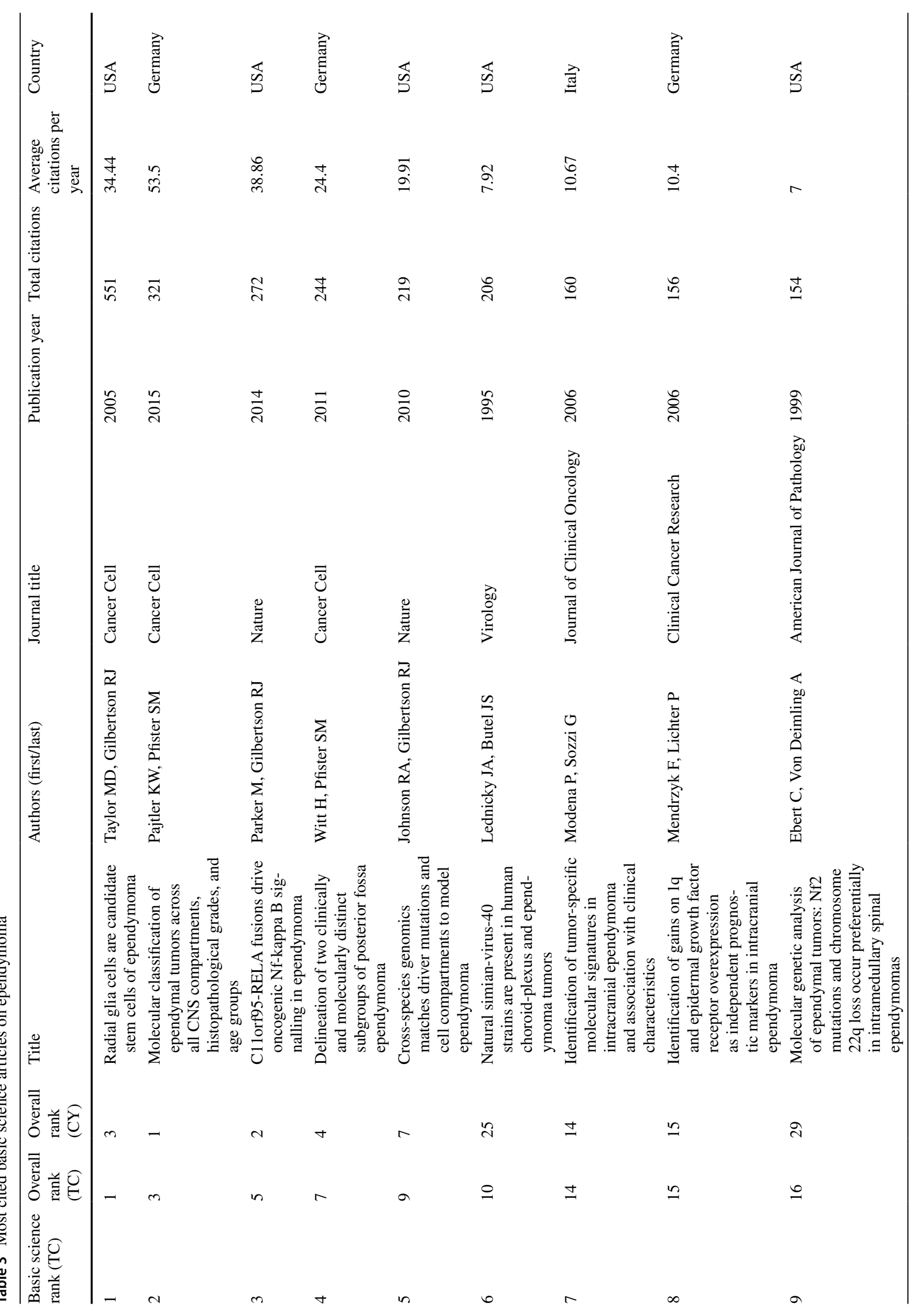




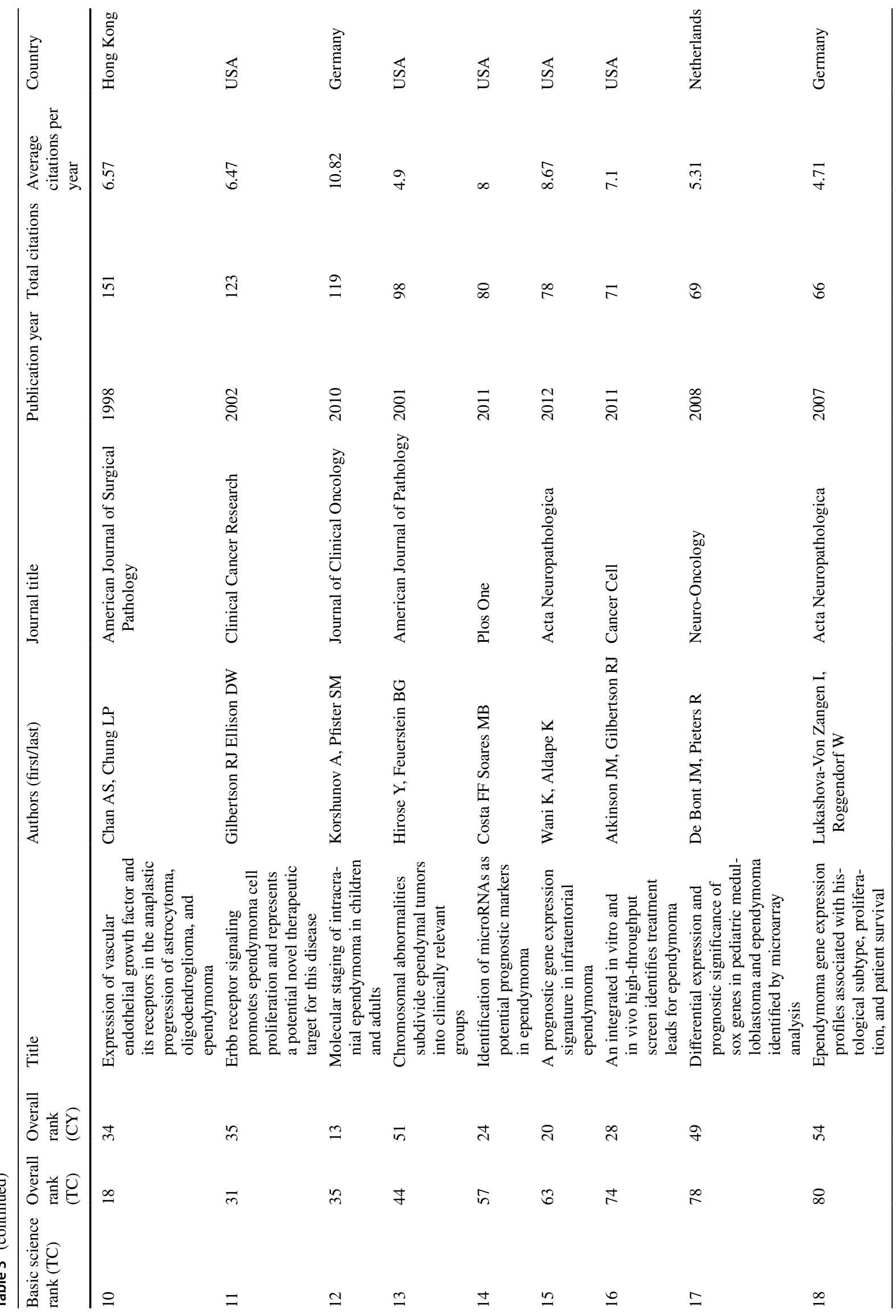


ependymoma: biological perspectives" and was published in Molecular Cancer Research in 2009 (Table 1) [22].

As shown in Fig. 1, the time period from 2005 to 2009 oversaw the publication of the greatest number of articles on the list (24 papers). This was followed by 2000-2004 and 1995-1999 (16 papers each) (Fig. 1). Total citations (2870) and average citations per year (204) were also highest for papers published in 2005-2009 (Fig. 2).

\section{Journal of publication}

The top 100 cited articles on ependymoma were published in 35 unique journals. The most frequent journals featuring the top cited articles included International Journal of Radiation Oncology Biology Physics (13\%), Cancer (10\%), and Journal of Neurosurgery (9\%) (Table 5). Of the top 10 most cited, 3 articles were published in Cancer Cell, followed by 2 articles each in Nature and Cancer.

\section{Countries and institutions}

A total of 13 countries represented the top 100 articles published (Fig. 3). The USA $(n=63)$, Germany $(n=8)$, and the UK $(n=7)$ were the highest contributors of the top 100 articles. The top institutions contributing the greatest number of articles among the top 100 most cited articles were St. Jude Children's Research Hospital $(n=16)$, the University of Texas MD Anderson Cancer Center $(n=6)$, and the German Cancer Research Center $(n=5)$ (Table 6). The USA contributed 5 of the top 10 most cited articles.

\section{Article category}

Each article was categorized as either basic science (19\%), clinical (74\%), or literature review (7\%) (Table 1; Fig. 1). Studies are separated into basic science and clinical studies and ranked by times cited in Tables 3 and 4, respectively. Of the top 10 articles, 6 were basic science articles and 4 were clinical articles. Of the top 20, 10 were basic science articles, and 10 were clinical articles.

\section{Citations per year}

Since articles published more remotely are advantaged in terms of collecting citations over time, we examined the citation frequency per year. Using this metric, the article with the greatest number of citations per year (53.5) was a basic science article entitled "Molecular classification of ependymal tumors across all CNS compartments, histopathological grades, and age groups," published in Cancer Cell in 2015 (Table 2) [42]. Comparatively, the clinical article with the most citations per year - "Conformal radiotherapy after surgery for pediatric ependymoma: a 


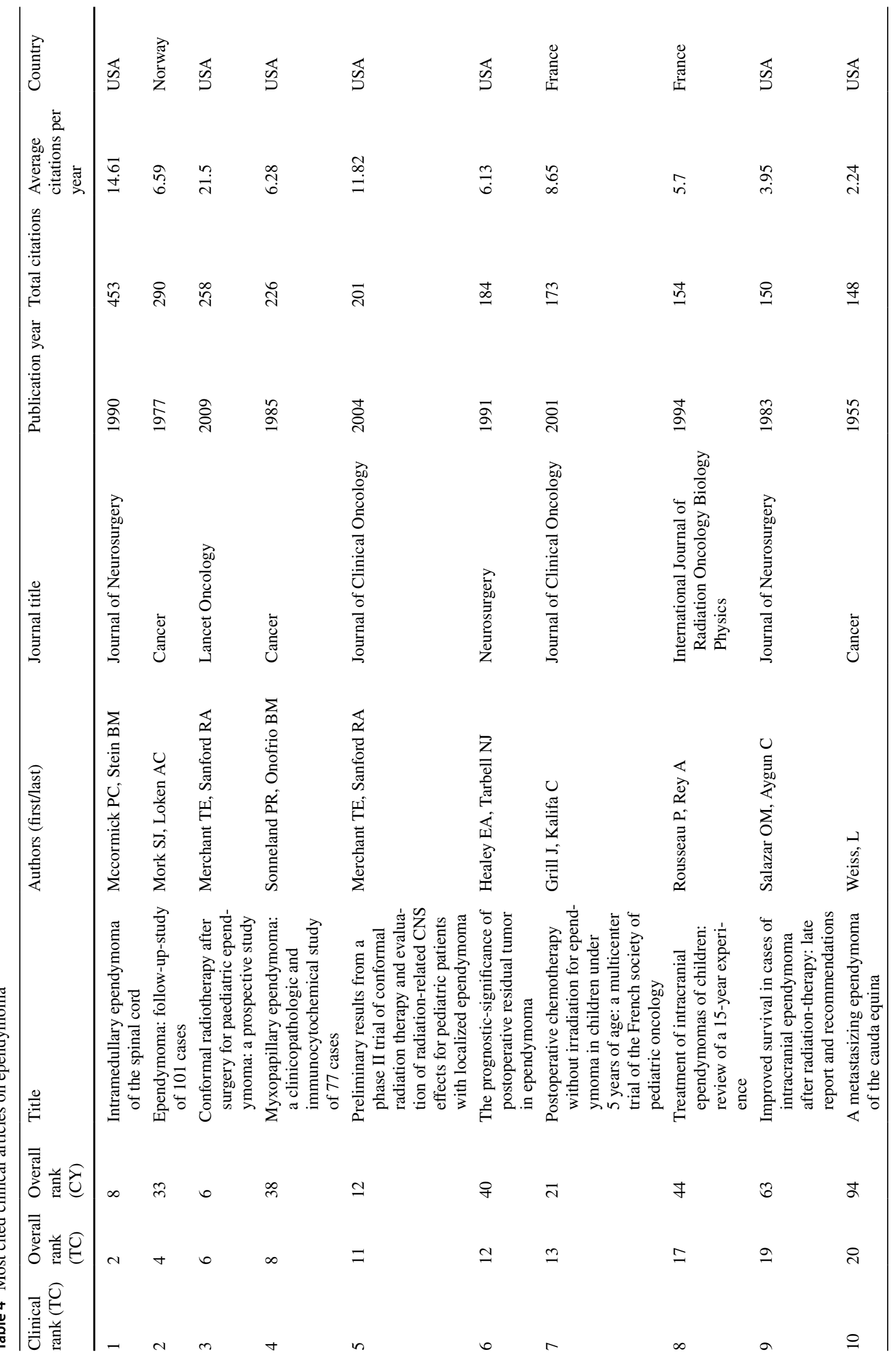




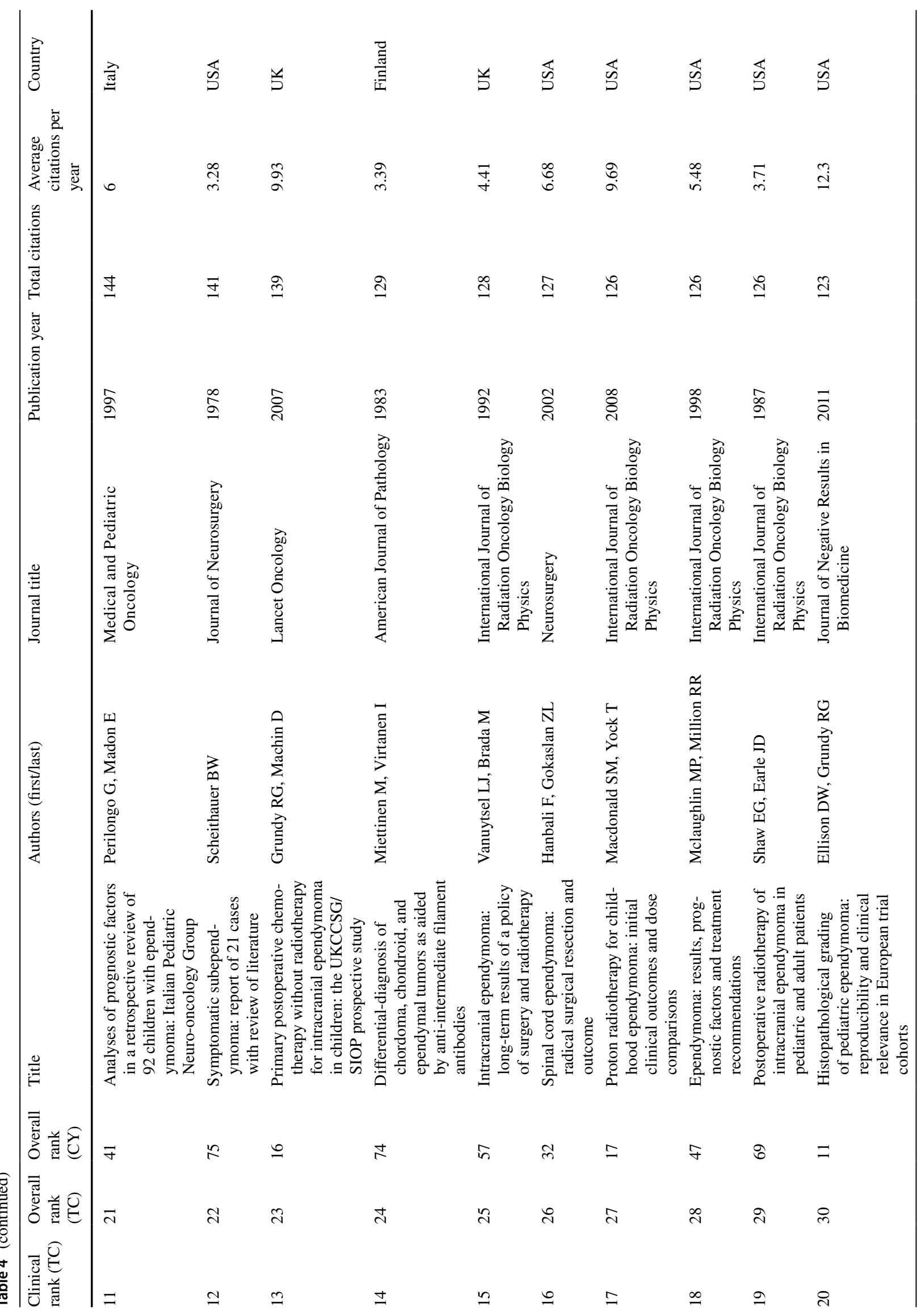




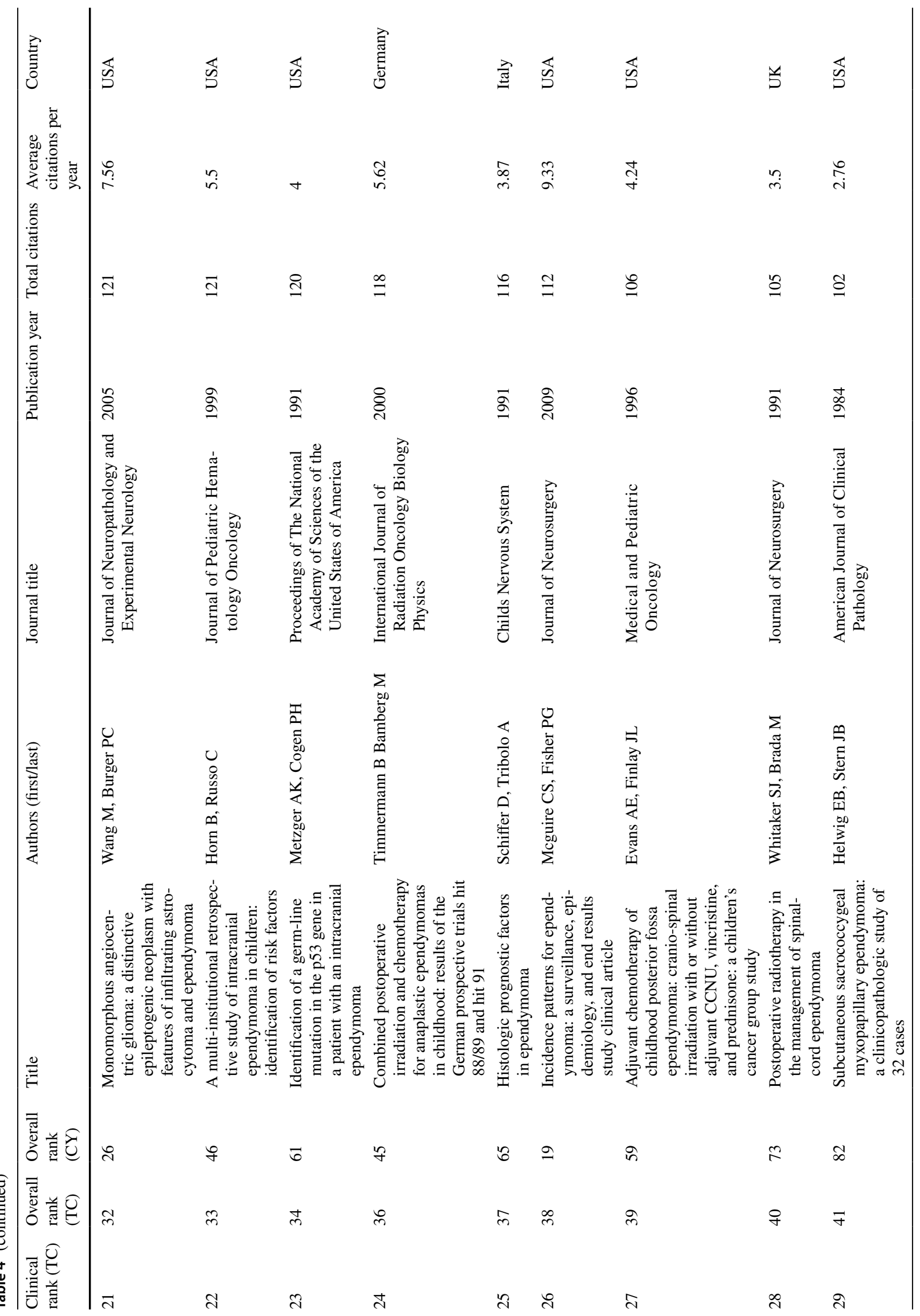




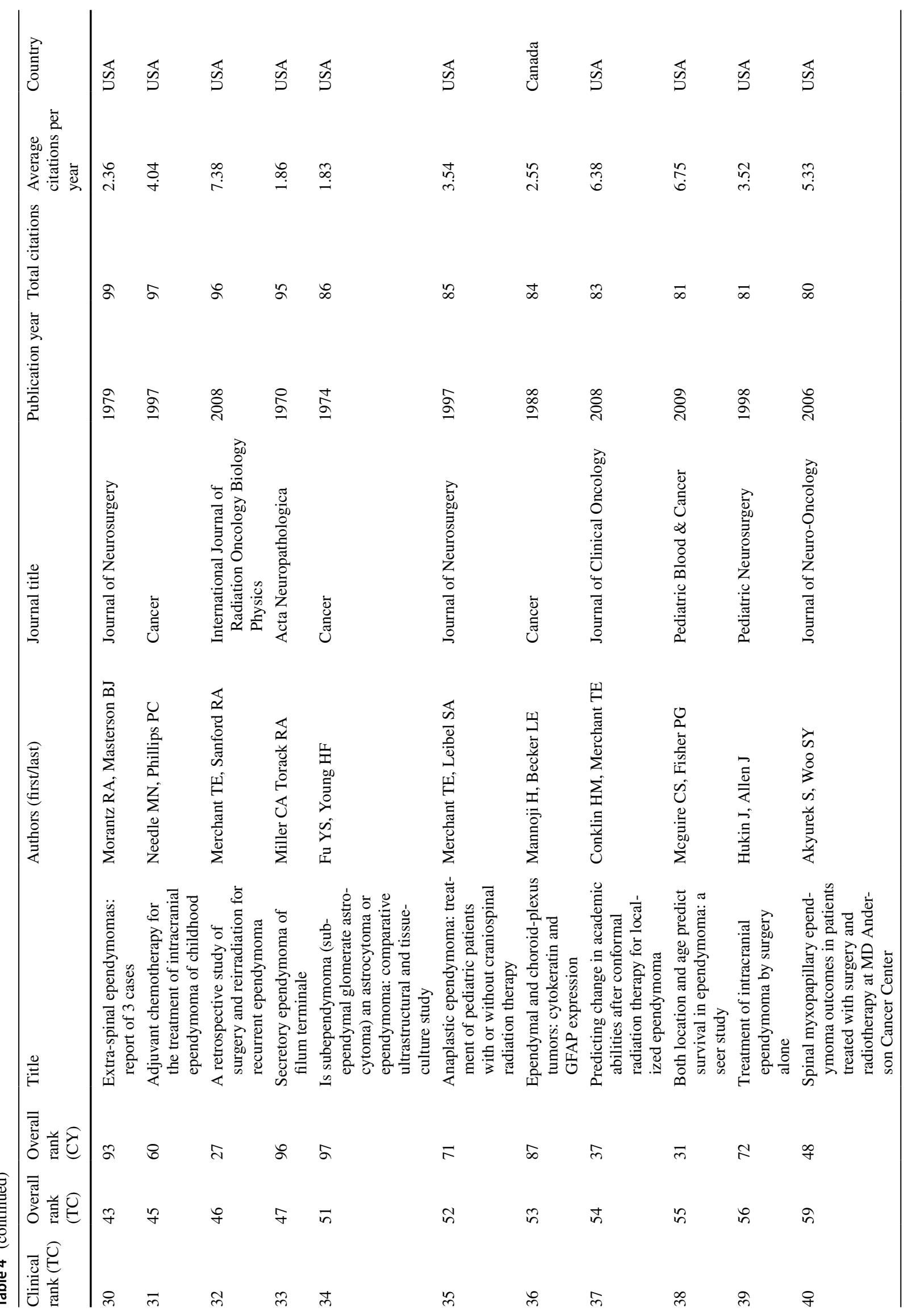




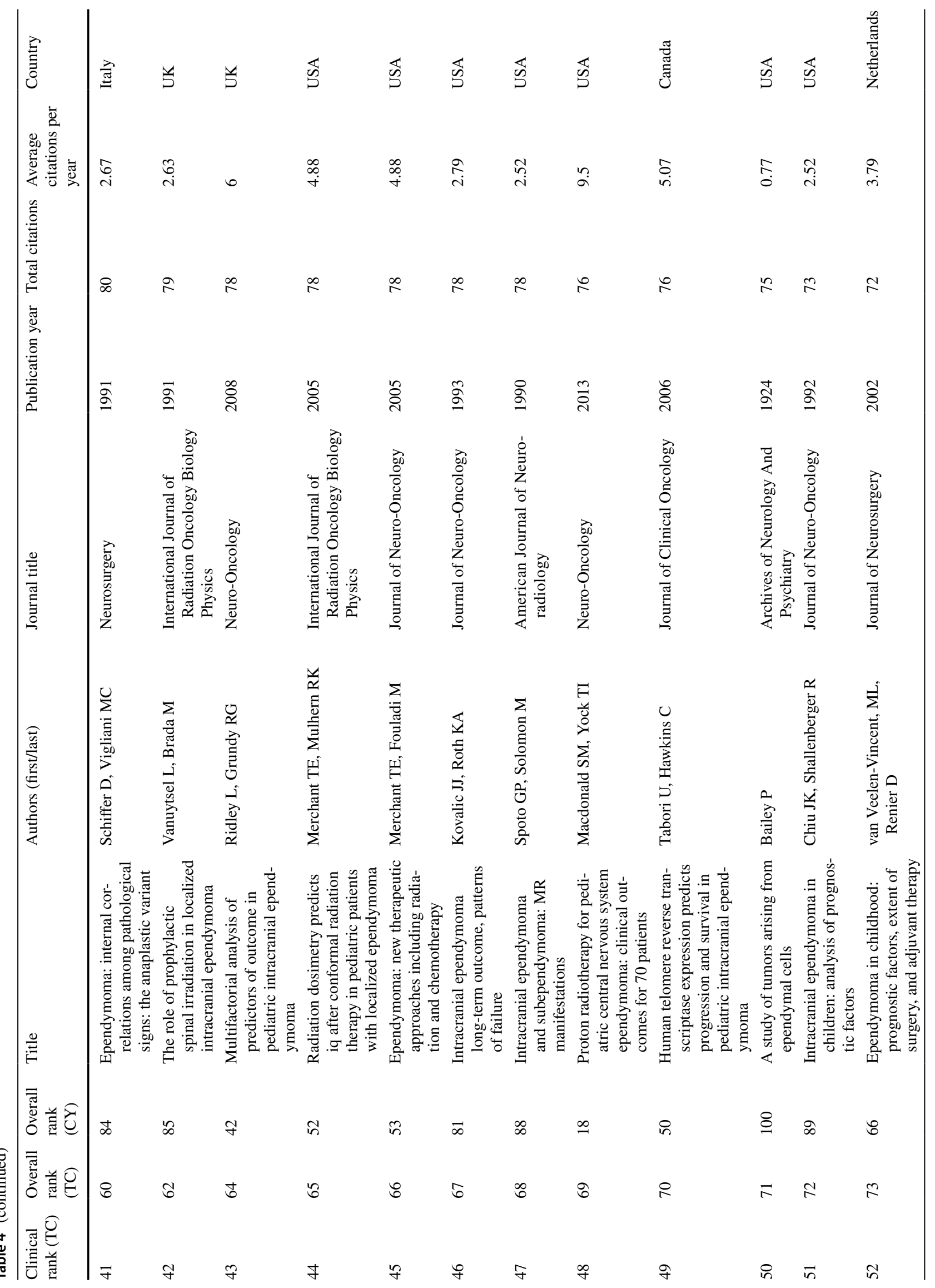




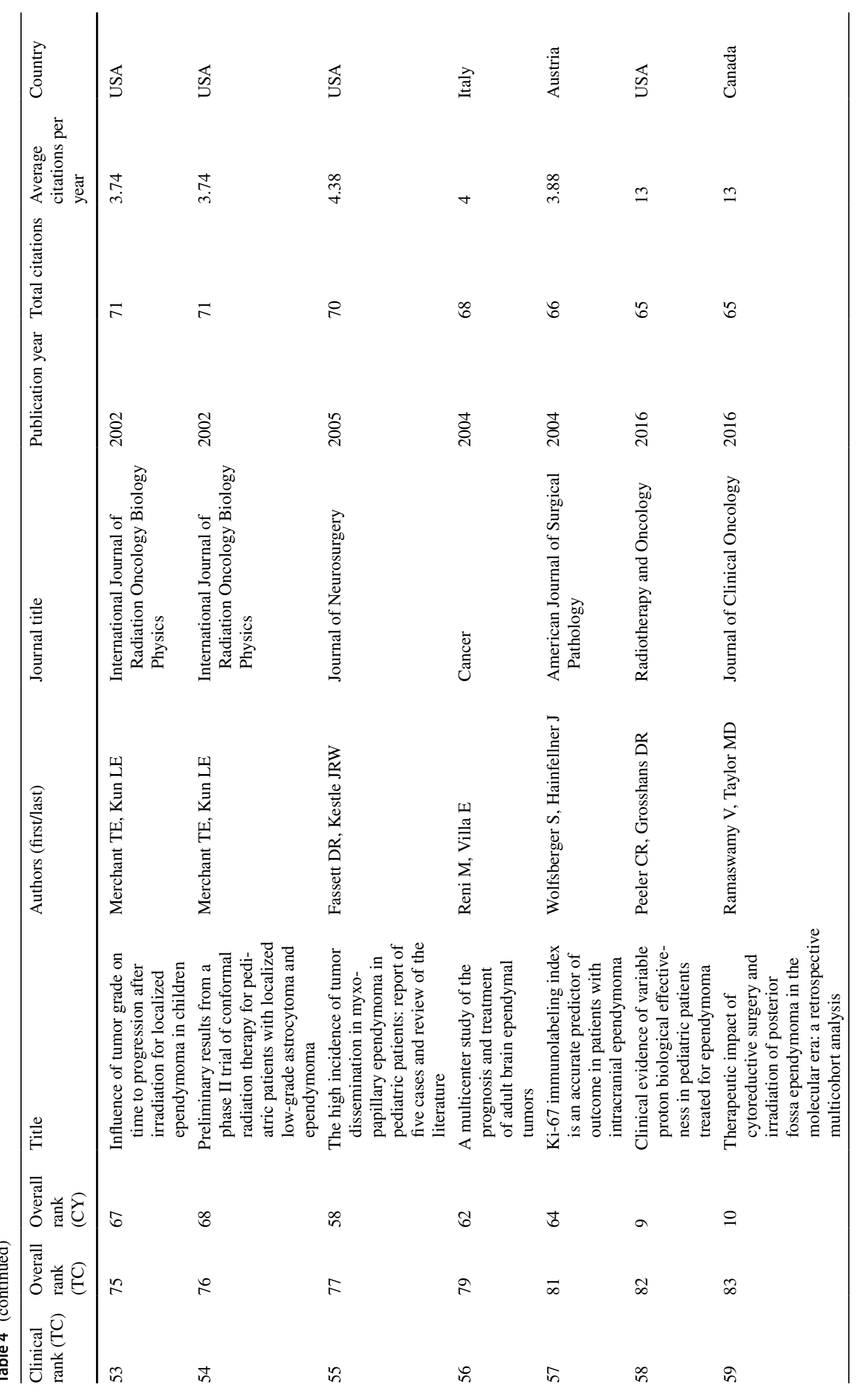




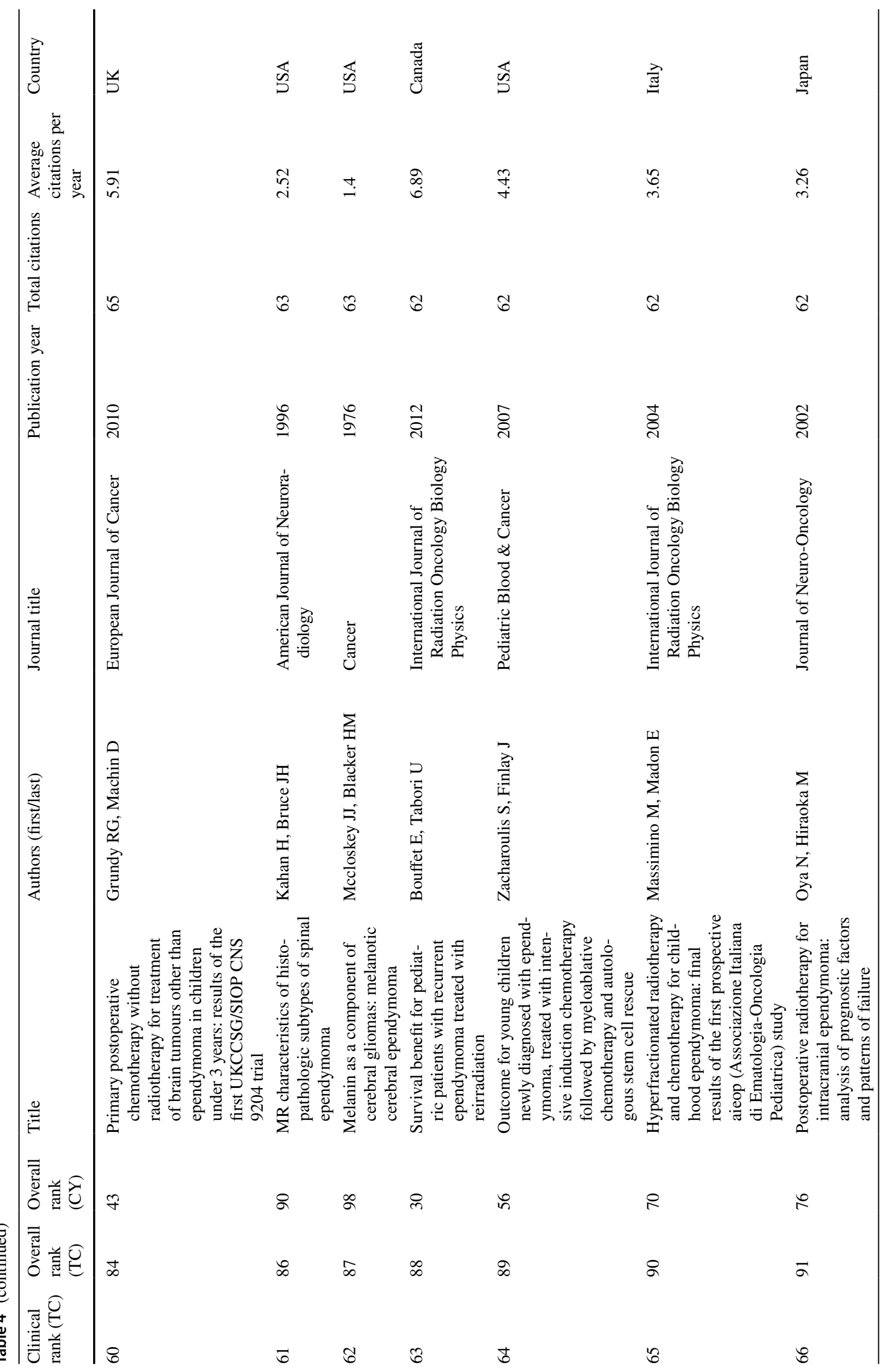




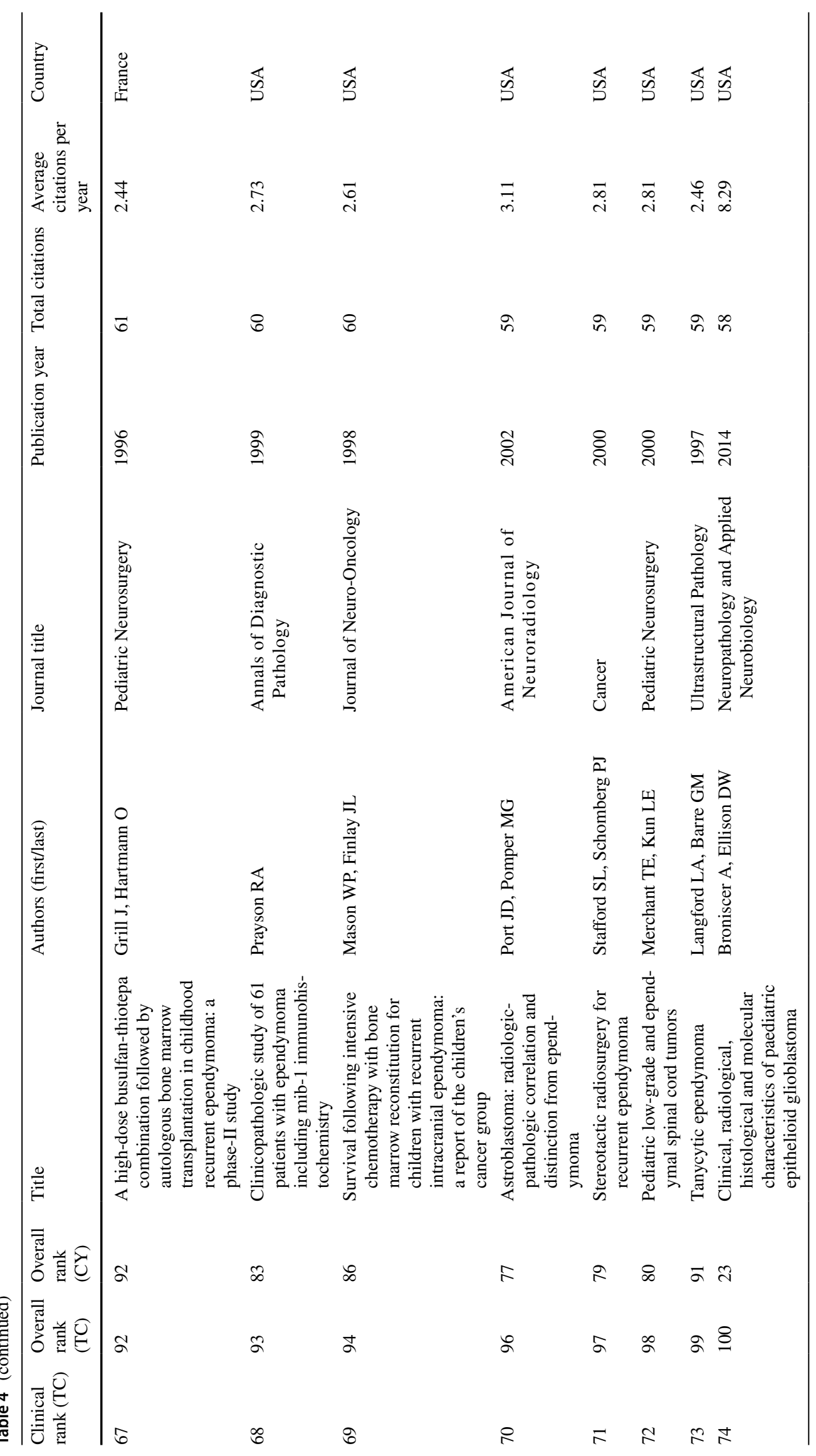


Fig. 1 Proportion of clinical, basic science, and review articles that were published over each 5-year period, starting in 1970

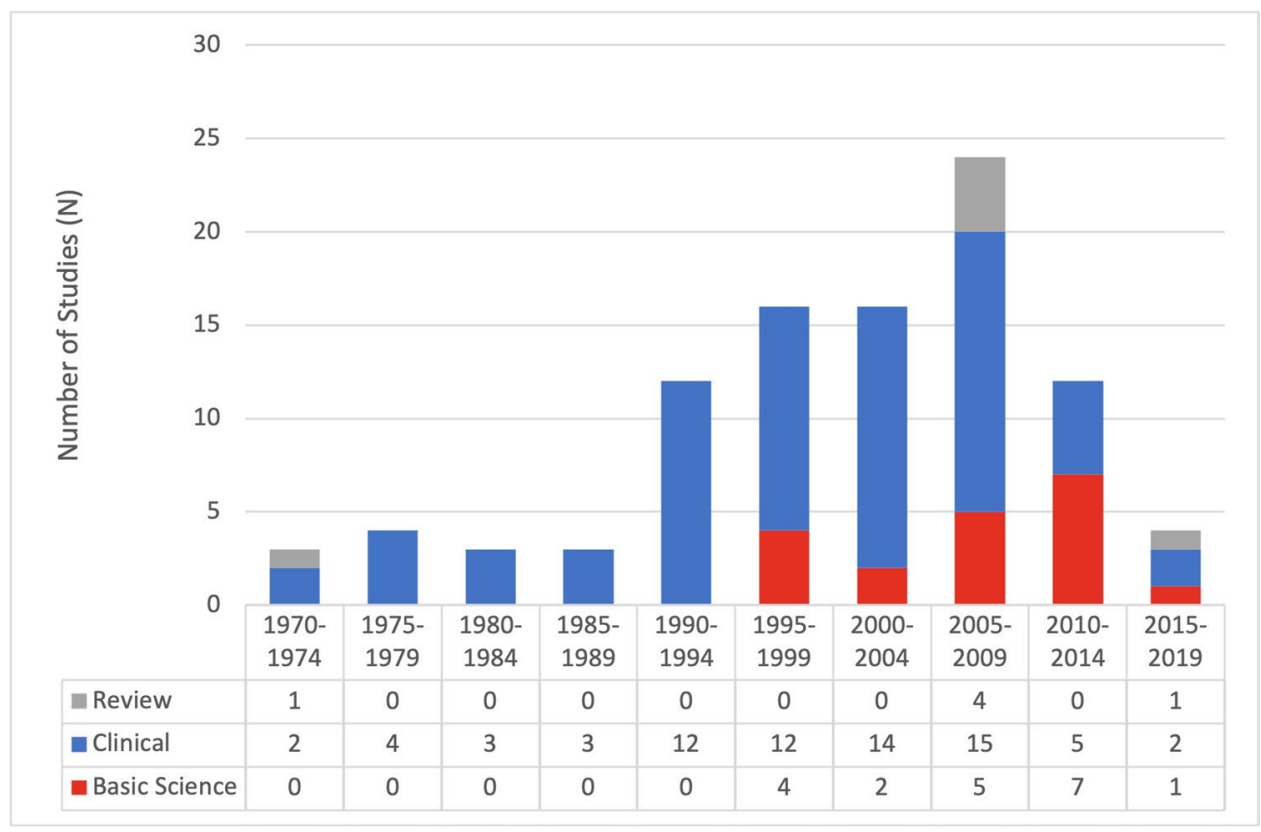

prospective study," published in Lancet Oncology in 2009 - averaged far fewer (21.5) (Table 2) [35].

\section{Authors}

The first and senior authors of each paper in the top 100 list were analyzed (Table 1). Thomas E. Merchant from St Jude Children's Research Hospital authored the greatest number of articles (10), followed by Richard G. Grundy (5) from Children's Brain Tumour Research Centre,
University of Nottingham, and Richard J. Gilbertson (4) from St Jude Children's Research Hospital (Fig. 4).

\section{Discussion}

This study identifies the most widely cited articles related to the understanding of ependymoma. Our bibliometric analysis revealed 100 articles published across 35 distinct journals, which highlighted a broad international interest
Fig. 2 Total citations and average citations per year for articles that were published over each 5-year period

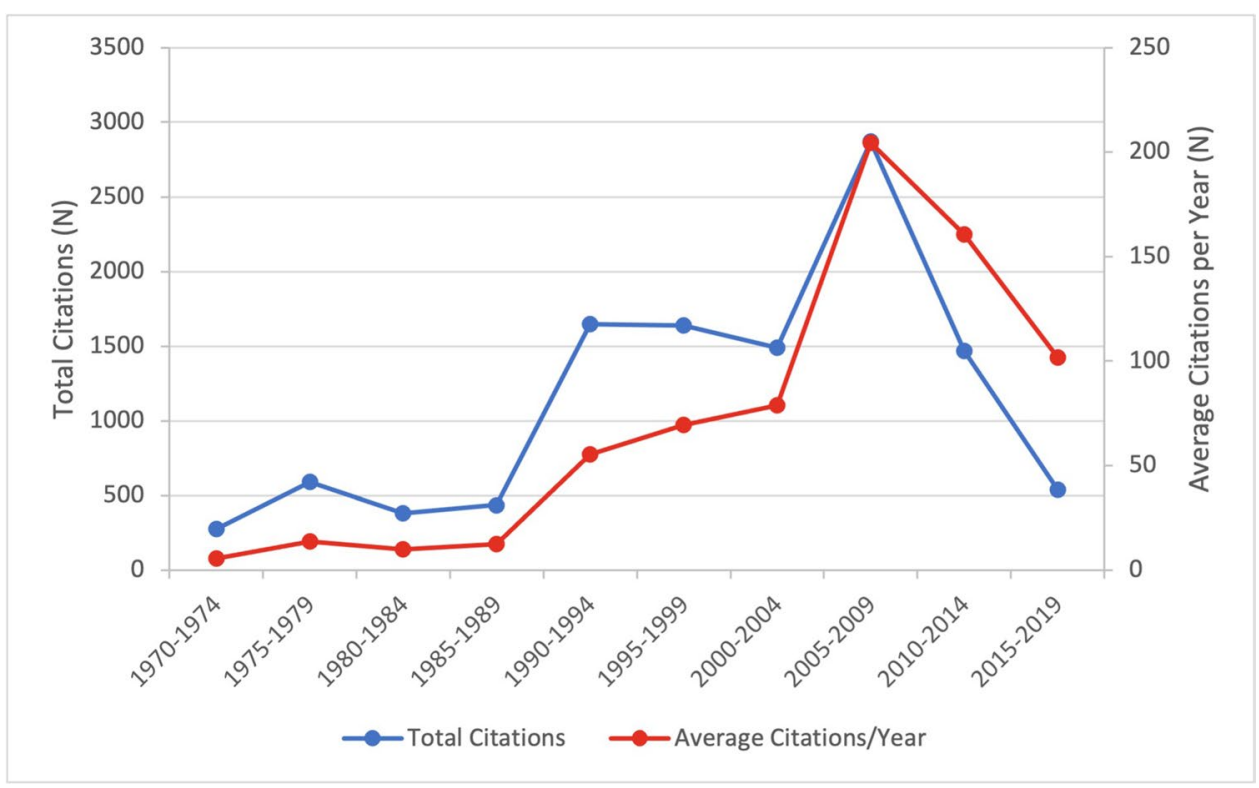


Table 5 Number of articles per journal
Journals of publication

Number

of articles

$(\mathrm{n}=100)$

International Journal of Radiation Oncology Biology Physics

13

Cancer

10

Journal of Neurosurgery

Journal of Clinical Oncology

9

Journal Of Neuro-Oncology

Acta Neuropathologica

Cancer cell

Neuro-Oncology

American Journal of Neuroradiology

American Journal of Pathology

Neurosurgery

Pediatric Neurosurgery

American Journal of Surgical Pathology

Clinical Cancer Research

Journal of Neuropathology and Experimental Neurology

Lancet Oncology

Medical and Pediatric Oncology

Nature

Pediatric Blood \& Cancer

7

6

4

4

4

3

3

3

3

2

2

2

2

2

2

2

Other *
Fig. 3 Proportion of articles coming from each country of origin. The category "other" includes Japan, Austria, Hong Kong, Finland, and Norway, each of which had 1 article

\section{Articles by Country of Origin}

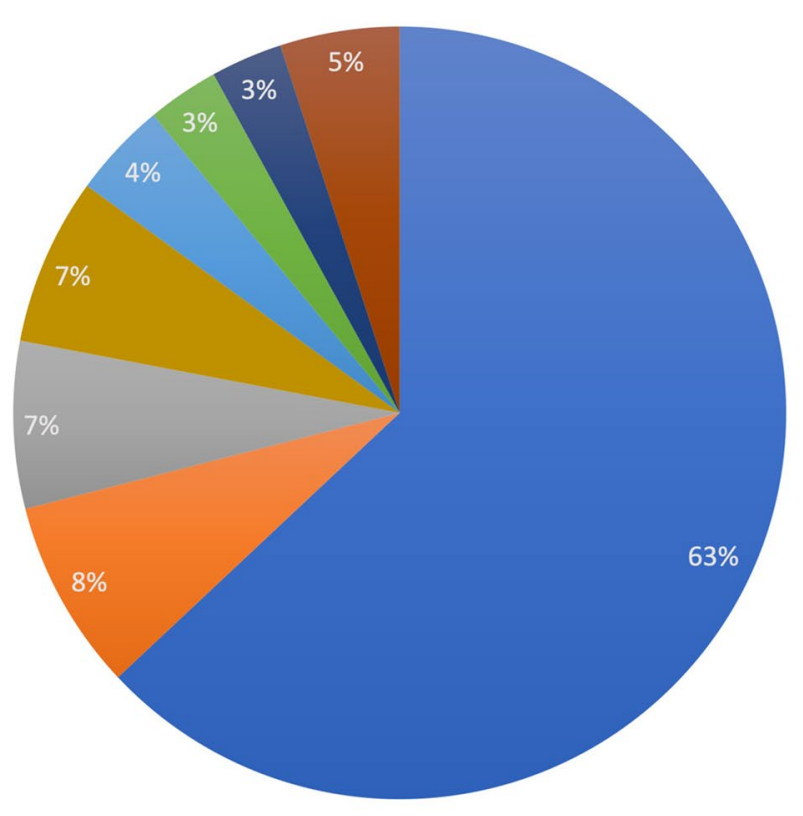

USA

- Germany

UK

Italy

- Canada

Netherlands

France

Other 
Table 6 Top institutions (based on first author)

\begin{tabular}{lll}
\hline Institution & Country & $\begin{array}{l}\text { Number of } \\
\text { articles }\end{array}$ \\
\hline St Jude Children's Research Hospital & USA & 16 \\
The University of Texas MD Anderson Cancer Center & USA & 6 \\
German Cancer Research Center & Germany & 5 \\
Hospital for Sick Children & Canada & 4 \\
Mayo Clinic & USA & 4 \\
Stanford University & USA & 4 \\
Royal Marsden Hospital & UK & 3 \\
University of Nottingham & UK & 3 \\
Children's Hospital of Philadelphia & USA & 2 \\
Institut Gustave Roussy & France & 2 \\
Istituto Nazionale Tumori & Italy & 2 \\
Memorial Sloan-Kettering Cancer Center & USA & 2 \\
San Raffaele Scientific Institute & Italy & 2 \\
Sophia Children's Hospital & Netherlands & 2 \\
University of California, San Francisco & USA & 2 \\
Washington University School of Medicine & USA & 2 \\
University of Turin & Italy & 2 \\
\hline
\end{tabular}

in ependymoma research. While a large majority of the top 100 cited articles were clinical $(74 \%)$, basic science research (19\%) comprised half of the top 20 most cited articles. This is likely the result of a recent focus on novel molecular classifications for the disease, as well as an effort to better understand the biochemical underpinnings of its development to guide therapeutic strategies. The large volume of literature focused on ependymoma research can pose a challenge for anyone searching for significant, impactful studies in the field [17]. Our hope is that this bibliometric analysis informs researchers in their efforts to understand the most relevant and significant literature relating to ependymoma.

It is important to note that while overall citation number is an important indicator of an article's impact and importance, it can be misleading in older articles that have more time to be cited with each passing year. To account for this, our analysis included another important metric: citations per year (Table 2). As an example, the article ranked sixth overall on our list — "Conformal radiotherapy after surgery for pediatric ependymoma: a prospective study" published in Lancet Oncology in 2009 — also ranked sixth in citations per year [35]. This article reported a high rate of local tumor control and event-free survival following aggressive surgical intervention and adjuvant high-dose conformal radiotherapy in pediatric patients, including those younger than 3 years of age [35]. Its presence within the top 10 in both overall and average yearly citations indicates its continued relevance in our understanding of ependymoma, particularly for pediatric patients, despite having been published over ten years ago.
In bibliometric analyses, it is not uncommon to find several articles with drastically different positions on these two lists. Such articles tend to be highly impactful articles published very recently. Two such articles on our list worth examining in closer detail are studies by Peeler et al. and Ramaswamy et al. in 2016. Ranked 81st and 82nd overall and 9th and 10th in citations per year, respectively, these two studies provided novel insights into two well-established treatment modalities. Specifically, Peeler et al. discovered that proton therapy-induced damage to normal tissue dependent on the physical radiation dose and track-averaged linear energy transfer, one of the main determinants of proton therapy's biological effectiveness [45]. Ramaswamy et al. reported that incomplete resection of molecular variant EPN_PFA (posterior fossa ependymoma A) ependymomas was associated with poor prognosis and that adjuvant radiation is preferred for patients with complete resections, while delayed external-bean radiation is preferred for relapsing cases of EPN_PFB (posterior fossa ependymoma B) tumors [46]. Both articles highlight critical discoveries in our understanding of current therapeutics for ependymoma, so it is unsurprising that they have each been given considerable attention since publication. Their place on the overall citation list is likely just a consequence of having less time to gather citations.

A closer examination of the top 20 articles in particular revealed a trend with respect to article type and publication year. Clinical articles within the top 20 tended to be published earlier (i.e., 1955 to 2009), while basic science 


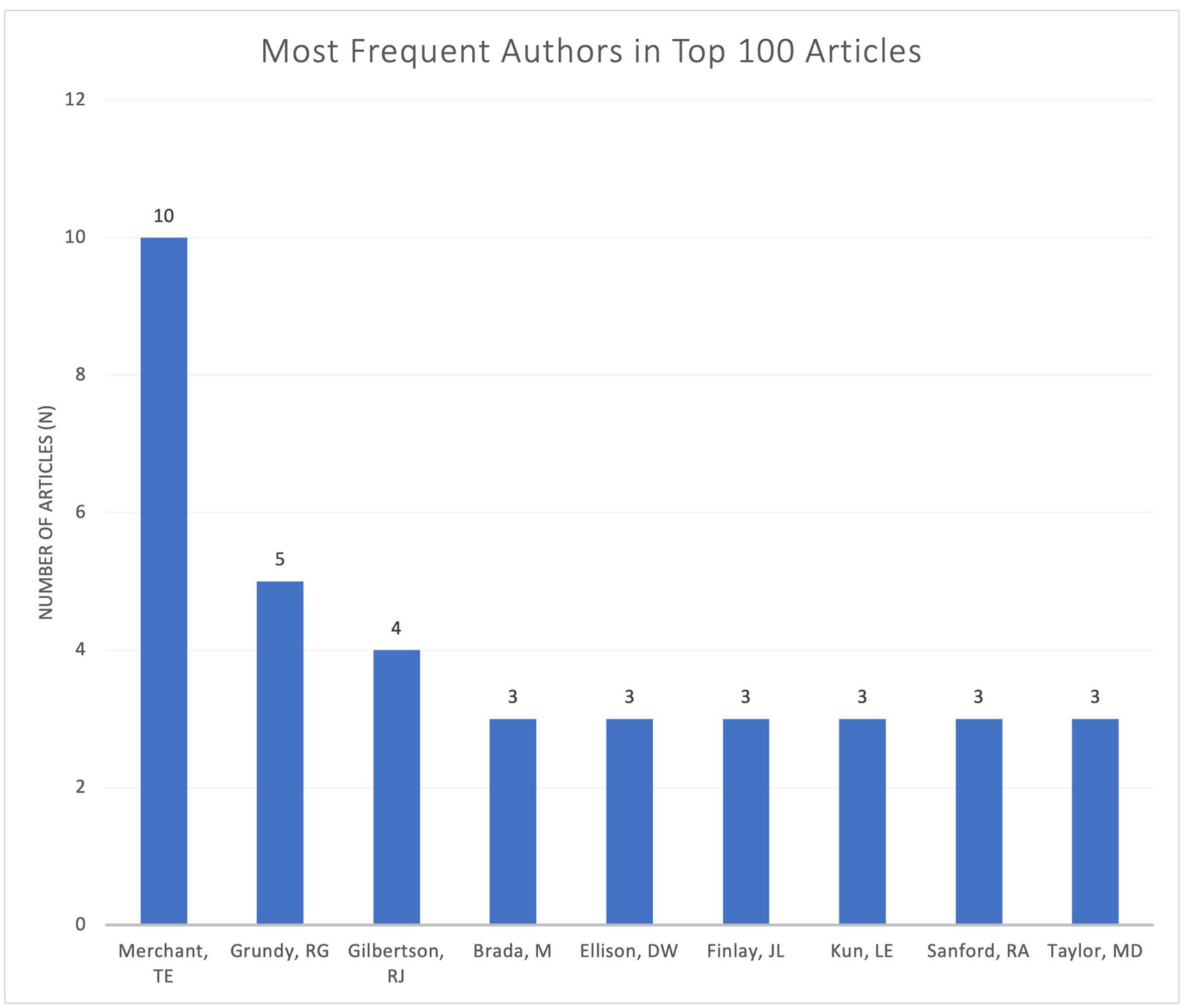

Fig. 4 Number of articles published by the most common authors based on presence as either first or last author in the top 100 most cited articles

articles tended to be published later (i.e., 1995 to 2015). Logically, the basic science articles in the top 20 had higher average citations per year (21.4) than clinical articles (8.7). These clinical articles tended to focus on the initial clinical presentations and pathophysiologic prognosticators of the disease, much of which is considered common knowledge today. One such article, entitled "Ependymoma: follow-up study of 101 cases," published in Cancer in 1977 (fourth most cited overall), managed to follow a cohort of patients who underwent ependymoma treatment over a considerable period of time (22 years) [37]. The authors reported favorable clinical outcomes in cases of spinal ependymoma, which more commonly affects adults (10-year survival of $72 \%$ ), compared to intracranial ependymoma, which more commonly affects children (10-year survival of 13\%) [37]. They also reported a survival benefit with postoperative radiation therapy but failed to find much prognostic value in tissue histopathology, an issue still under debate in current literature [27, 52, 57, 59]. Given the extensive followup reported by the authors as well as the relatively novel findings with respect to clinical course of ependymoma at the time of publication (1977), it is not surprising that this clinical article has maintained citation prevalence to date. The article entitled "Myxopapillary ependymoma: a clinicopathologic and immunocytochemical study of 77 cases," published in Cancer in 1985 and eighth overall on our list, is another example of a clinical article that has maintained relevance despite its remote publication date [50]. This study focused on gross tumor characteristics as prognosticators for postoperative course, reporting that certain physical findings, such as the presence of a tumor capsule, were more indicative of prognosis than histological features [50]. Since 
the publication of these and other similar clinical articles, advances in biomolecular research have improved our understanding of the molecular underpinnings of ependymomas. Such advances have likely contributed to the recent shift in focus from ependymoma's clinical characteristics and prognostic factors to biomolecular properties of the disease. Continued scientific interest in ependymoma molecular biology, technological advancements, and new innovations may eventually give rise to novel treatments, such as small molecule and personalized precision medicine therapies [39, 44, 54].

The top cited clinical studies on ependymoma are most often case series describing key clinical features, diagnostic modalities, different treatment regimens, and outcomes. One common theme among studies is that GTR is the single factor most consistently associated with improved survival and reduced recurrence compared to subtotal resection (STR) $[15,18,35,36,47,50]$. There were no prospective randomized controlled trials in the top 100 most cited articles. The most cited clinical article (ranked second overall) titled "Intramedullary ependymoma of the spinal cord," was published in 1990 and described a retrospective series of 23 patients who underwent surgical resection of this entity [34]. All tumors were histologically benign, gross total resection was achieved in all cases, and no recurrences were reported. Other series reported outcomes in various treatment strategies combining surgical resection, radiation therapy, and chemotherapy. For instance, the 19th most cited study (by Salazar et al. published in the Journal of Neurosurgery in 1983) was one of the first studies to establish efficacy of adjunctive radiotherapy in ependymoma treatment [48]. The authors reported a 10 -year overall survival of $69 \%$ in a series of patients with intracranial ependymoma treated with resection and whole-brain radiation therapy [48]. The progression from whole-brain radiation to localized radiation was demonstrated in a more recent prospective trial by Merchant et al. in 2009. These authors published a large series of 153 pediatric patients who underwent surgery and conformal radiation therapy (CRT) and reported $85 \%$ overall survival in patients who received CRT without delay [35]. In addition to their excellent outcomes, this study irradiated pediatric patients younger than 3 years old, which has been historically avoided due to concerns for delayed radiation neurotoxicity [16]. The role of adjunctive chemotherapy in ependymoma treatment was the topic of two prospective trials that were 13th [15] and 23rd [16] most cited studies overall. The 13th most cited study involved treatment of 73 children with primarily high-grade ependymoma with surgery and chemotherapy, without radiation [15]. The authors reported a low 4-year progression-free survival rate at $22 \%$ and overall survival rate of 59\% [15]. The 23rd most cited study treated 89 children aged 3 years or younger with surgical resection and chemotherapy. Similarly, disease progression occurred in $62.5 \%$ of patients with non-metastatic disease, and overall survival at 5 years was $63.4 \%$ [16]. Notably, the authors did report that higher doses of chemotherapy were associated with improved 5-year overall survival compared to low doses (76\% vs. 52\%) [16].

Several clinical studies were lower in overall citations but higher in citations per year, suggesting that they are impactful articles published more recently. For instance, the study entitled - "Histopathological grading of pediatric ependymoma: reproducibility and clinical relevance in European trial cohorts," published in 2011 was 30th in overall citations but 11th in citations per year [11]. This study developed a novel method for ependymoma grading that demonstrated higher concordance among pathologists than the traditional WHO grading method. However, the study found little correlation between ependymoma grade and clinical outcomes, calling into question the clinical utility of histological grading of ependymoma [11]. Two studies ranked 9th [45] and 17th [26] in average citations per year, utilized proton beam radiation for adjunctive ependymoma treatment. Peeler et al. created linear regression models correlating proton beam radiation dose and linear energy transfer with post-treatment changes on imaging. This demonstrated objective clinical changes caused by proton beam radiation, although did not report patient outcomes such as overall or progression-free survival [45]. On the other hand, MacDonald et al. reported excellent 2-year overall survival (89\%) and progression-free survival $(80 \%)$ in 17 pediatric patients treated with proton therapy after surgical resection. These studies together may represent a promising new adjunct to GTR in the treatment of ependymoma. Finally, as previously mentioned, one study ranked 83 rd overall and 10 th by citations per year addressed the effect of distinct molecular profiles of posterior fossa ependymoma on outcomes after surgery and radiation [46]. The authors report EPN_PFA was a highly significant predictor of poor progression-free survival (hazard ratio [HR], 2.14; 95\% confidence interval [CI], 1.31 to 3.49 , $P=0.002)$ and overall survival (HR, $4.30 ; 95 \% \mathrm{CI}, 1.88$ to 9.87; $P<0.001)$. Conversely, EPN_PFB was associated with excellent 10-year overall survival of $96.1 \%$ after GTR [46]. These findings in this recent article with a high citations per year count highlight the new appreciation of ependymoma molecular subtyping in treatment prognosis.

The WHO grading criteria for ependymoma based on tumor histopathology (most recently updated in 2016) have been shown to have poor predictive value for overall survival for the disease [27]. Given the limited clinical utility of these criteria, recent research has focused on understanding the molecular biology of ependymoma to improve on our current prognostic capabilities [27]. Six of the 10 most cited articles were basic science studies aimed at addressing the issue of ependymoma subtyping. The top article overall, entitled "Radial glia cells are candidate stem cells of ependymoma," published in Cancer 
Cell in 2005, found that supratentorial, infratentorial, and spinal cord ependymomas are derived from radial glial cells [51]. From this, the authors suggested that histologically similar ependymomas from different regions of the central nervous system represent molecularly distinct diseases and that ependymomas have gene expression profiles that resemble regionally specific radial glial cells. More recently, the article entitled "C11 orf95-RELA fusions drive oncogenic NF-kappa B signalling in ependymoma" published in Nature in 2015 elaborated upon the genetic underpinnings of a well-known oncogenic pathway $(\mathrm{NF}-\kappa \mathrm{B}$; nuclear factor kappa-light-chain-enhancer of activated $\mathrm{B}$ cells), which was found to exist in twothirds of supratentorial ependymomas [43]. Subsequently, a RELA fusion-positive (grade II or III) ependymoma subtype was included in the 2016 WHO Classification of Tumors of the CNS [12].

Another 2015 study focusing on ependymal classification - "Molecular classification of ependymal tumors across all CNS compartments, histopathological grades, and age groups" published in Cancer Cell ranked third overall and first in citations per year [42]. This study used DNA methylation profiling to identify nine distinct molecular subgroups of ependymoma and subcategorized each according to its location within the CNS (supratentorial, posterior fossa, and spine) [42]. The novel predictive system developed by this study outperformed previously published histopathological classifications in predicting overall and progression-free survival. The DNA-methylation-specific categorization was not included in the 2016 WHO Classification of Tumors of the CNS likely because DNA methylation profiling is only available in restricted institutions [23] and is therefore not amenable to widespread implementation [41]. Collectively, the recent momentum favoring biomolecular research in ependymoma has led to a more robust classification system for the disease, which will allow for improved prognostication and narrowed molecular targeting for therapeutic development. Such advancements are imperative given the high (40\%) prevalence of incurable tumors, poor postoperative prognosis, and chemotherapyresistant properties of ependymomas [19, 43, 51]. Continued research will reveal the impact of these basic science investigations on the therapeutic and diagnostic landscape of these tumors.

\section{Limitations}

This study has several limitations. First, as previously discussed, our list of the top 100 most cited papers was generated based on the total number of citations, which is subject to bias towards papers published earlier [3, 10]. Conversely, more recently published articles are often shown more frequently in research databases, which may also contribute to bias. To address this issue, we included data on the total number of citations (Table 1) and average citations per year in our analysis (Table 2), in order to provide a comprehensive view of ependymoma research. This analysis also demonstrated that basic science articles have enjoyed more citations on average in the last 10 years than clinical articles. Taken in combination with overall citation data, these findings suggest that the current direction of ependymoma research will focus more heavily on research examining the biomolecular characteristics of ependymoma. Second, while WoS is the most commonly used and validated resource for bibliometric analyses, it is not comprehensive of all medical literature and does not include citations from textbooks or non-English journal articles [10, 17]. Our WoS search was also title-specific, which may have led to the unintentional exclusion of relevant papers in the top 100 list since abstracts and fulltext articles were not included in the search. Third, bibliometric analyses carry the inherent limitation that the citation frequency does not always correlate with impact. For instance, a basic science article published in 2016 on childhood posterior fossa ependymomas published in Science Translational Medicine determined that reduced H3K27me3 and DNA hypomethylation were associated with poor clinical outcomes [5]. However, this impactful study did not make the top 100 list. Fourth, our list is subject to inaccuracy due to the phenomenon of "obliteration by incorporation," whereby highly important articles can become less frequently cited over time as their ideas or findings become so widely accepted as to be considered common knowledge (and thus cited anonymously) [33]. As such, citation numbers may not always accurately reflect the influence or impact of studies, a limitation that is not completely addressed despite our using previously validated bibliometric analysis methodologies for CNS tumors [3, 17, 25]. Fifth, we categorized studies as basic science and clinical based on the focus of each article as previously performed [25]. However, this dichotomization did not account for studies that may be further subclassified as translational in nature. Despite these limitations, this article seeks to present publishing trends within the ependymoma literature and provides a categorized reference of articles and synthesis that will be helpful for future clinical trainees and scientists in the neuro-oncological and neurosurgical fields.

\section{Conclusion}

This study used a validated bibliometric analysis to identify the top 100 most cited articles on ependymoma. Careful examination of the list, in conjunction with another 
important metric - average number of citations per year - helps paint a picture of the history and behavior of ependymoma research over the last 50 years, as its focus migrated from clinical correlates and histopathologic prognosticators to genetic and molecular underpinnings of the disease. That we observe a high proportion of recently published basic science articles in the top 20 papers of our list points to a tendency to improve upon what were once widely accepted histopathological grading criteria. Ependymomas are chemotherapy-resistant, and a large proportion of tumors are incurable even with surgery and radiotherapy. Our results suggest that the field of ependymoma research is moving towards a more robust basic biological understanding and molecular classification system to guide clinical decision-making and future research endeavors into potential therapeutic options.

Author contribution Nolan J. Brown composed the original draft, revised the draft, gathered data, and approved the final draft.

Bayard Wilson composed the original draft, revised the draft, gathered data, and approved the final draft.

Brian V. Lien composed the original draft, revised the draft, gathered data, and approved the final draft.

Alexander Himstead revised the draft, gathered data, and approved the final draft.

Ali R. Tafreshi revised the draft, gathered data, and approved the final draft.

Shane Shahrestani revised the draft, gathered data, and approved the final draft.

Jack Birkenbeuel revised the draft and approved the final draft.

Katelynn Tran revised the draft and is responsible for formatting and editing.

David Horton is responsible for data collection.

Anushka Paladugu is responsible for data collection.

Lydia R. Kirillova is responsible for data collection.

Chen Yi Yang revised the draft and is responsible for approval of the final draft.

Seth C. Ransom revised the draft and is responsible for approval of the final draft.

Alvin Y. Chan revised the draft and is responsible for approval of the final draft.

Ronald Sahyouni revised the draft and is responsible for approval of the final draft.

Isaac Yang is responsible for the original conception and approval of final draft.

Funding Dr. Isaac Yang reports is being supported by the UCLA Visionary Ball Fund Grant, Eli and Edythe Broad Center of Regenerative Medicine and Stem Cell Research UCLA Scholars in Translational Medicine Program Award, Jason Dessel Memorial Seed Grant, UCLA Honberger Endowment Brain Tumor Research Seed Grant, and Stop Cancer (US) Development Award. The sponsors had no role in the design or conduct of this research.

Data Availability All data and materials support published claims and comply with field standards.

Code availability Not applicable.

\section{Declarations}

Ethics approval Not applicable.

Consent to participate Not applicable.

Consent for publication Not applicable.

Conflict of interest The authors declare no competing interests.

Open Access This article is licensed under a Creative Commons Attribution 4.0 International License, which permits use, sharing, adaptation, distribution and reproduction in any medium or format, as long as you give appropriate credit to the original author(s) and the source, provide a link to the Creative Commons licence, and indicate if changes were made. The images or other third party material in this article are included in the article's Creative Commons licence, unless indicated otherwise in a credit line to the material. If material is not included in the article's Creative Commons licence and your intended use is not permitted by statutory regulation or exceeds the permitted use, you will need to obtain permission directly from the copyright holder. To view a copy of this licence, visit http://creativecommons.org/licenses/by/4.0/.

\section{References}

1. Alan N, Cohen J, Ozpinar A, Agarwal N, Kanter AS, Okonkwo DO et al (2017) Top 50 most cited articles on primary tumors of the spine. J Clin Neurosci 42:19-27

2. Alfaifi A, AlMutairi O, Allhaidan M, Alsaleh S, Ajlan A (2018) The top 50 most-cited articles on acoustic neuroma. World Neurosurg 111:e454-e464

3. Almutairi O, Albakr A, Al-Habib A, Ajlan A (2017) The top-100 most-cited articles on meningioma. World Neurosurg 107:10251032.e1025

4. Archer TC, Pomeroy SL (2015) Defining the molecular landscape of ependymomas. Cancer Cell 27(5):613-615

5. Bayliss J, Mukherjee P, Lu C, Jain SU, Chung C, Martinez D, et al (2016) Lowered H3K27me3 and DNA hypomethylation define poorly prognostic pediatric posterior fossa ependymomas. Sci Transl Med ;8(366):366ra161.

6. Boström A, von Lehe M, Hartmann W, Pietsch T, Feuss M, Boström JP, et al (2011) Surgery for spinal cord ependymomas: outcome and prognostic factors. Neurosurgery ;68(2):302-308; discussion 309.

7. Brown NJ, Wilson B, Shahrestani S, Choi EH, Lien BV, Paladugu A et al (2021) The 100 most influential publications on medulloblastoma: areas of past, current, and future focus. World Neurosurg 146:119-139

8. Cage TA, Clark AJ, Aranda D, Gupta N, Sun PP, Parsa AT et al (2013) A systematic review of treatment outcomes in pediatric patients with intracranial ependymomas. J Neurosurg Pediatr 11(6):673-681

9. Cohen J, Alan N, Zhou J, Kojo Hamilton D (2016) The 100 most cited articles in metastatic spine disease. Neurosurg Focus ;41(2):E10

10. De la Garza-Ramos R, Benvenutti-Regato M, Caro-Osorio E (2016) The 100 most-cited articles in spinal oncology. J Neurosurg Spine 24(5):810-823

11. Ellison DW, Kocak M, Figarella-Branger D, Felice G, Catherine G, Pietsch T, et al (2011) Histopathological grading of pediatric ependymoma: reproducibility and clinical relevance in European trial cohorts. J Negat Results Biomed ;10:7 
12. Fukuoka K, Kanemura Y, Shofuda T, Fukushima S, Yamashita S, Narushima D, et al (2018) Significance of molecular classification of ependymomas: C11orf95-RELA fusion-negative supratentorial ependymomas are a heterogeneous group of tumors. Acta Neuropathol Commun ;6(1):134

13 Garvin JH Jr, Selch MT, Holmes E, Berger MS, Finlay JL, Flannery A et al (2012) Phase II study of pre-irradiation chemotherapy for childhood intracranial ependymoma. Children's Cancer Group protocol 9942: a report from the Children's Oncology Group. Pediatr Blood Cancer 59(7):1183-1189

14. Gerstner ER, Pajtler KW (2018) Ependymoma. Semin Neurol 38(1):104-111

15. Grill J, Le Deley MC, Gambarelli D, Raquin MA, Couanet D, Pierre-Kahn A et al (2001) Postoperative chemotherapy without irradiation for ependymoma in children under 5 years of age: a multicenter trial of the French Society of Pediatric Oncology. J Clin Oncol 19(5):1288-1296

16. Grundy RG, Wilne SA, Weston CL, Robinson K, Lashford LS, Ironside J et al (2007) Primary postoperative chemotherapy without radiotherapy for intracranial ependymoma in children: the UKCCSG/SIOP prospective study. Lancet Oncol 8(8):696-705

17. Guo X, Gao L, Wang Z, Feng C, Xing B (2018) Top 100 mostcited articles on pituitary adenoma: a bibliometric analysis. World Neurosurg 116:e1153-e1167

18. Healey EA, Barnes PD, Kupsky WJ, Scott RM, Sallan SE, Black PM, et al (1991) The prognostic significance of postoperative residual tumor in ependymoma. Neurosurgery ;28(5):666-671; discussion 671-662.

19. Johnson RA, Wright KD, Poppleton H, Mohankumar KM, Finkelstein D, Pounds SB et al (2010) Cross-species genomics matches driver mutations and cell compartments to model ependymoma. Nature 466(7306):632-636

20. Kano H, Niranjan A, Kondziolka D, Flickinger JC, Lunsford LD (2009) Outcome predictors for intracranial ependymoma radiosurgery. Neurosurgery ;64(2):279-287; discussion 287-278

21. Kano H, Yang HC, Kondziolka D, Niranjan A, Arai Y, Flickinger JC et al (2010) Stereotactic radiosurgery for pediatric recurrent intracranial ependymomas. J Neurosurg Pediatr 6(5):417-423

22. Kilday JP, Rahman R, Dyer S, Ridley L, Lowe J, Coyle B et al (2009) Pediatric ependymoma: biological perspectives. Mol Cancer Res 7(6):765-786

23. Komori T (2017) The 2016 WHO classification of tumours of the central nervous system: the major points of revision. Neurol Med Chir (Tokyo) 57(7):301-311

24. Lien BV, Brown NJ, Himstead AS, Ball BZ, Guillen A, Acharya N, et al (2021) Surgical management of a rare myxopapillary ependymoma of the gluteal region: a case report. Surg Neurol Int [serial on the Internet]. 12: Available from: doi: https://doi.org/ 10.25259/sni_768_2020.

25. Lu VM, Power EA, Kerezoudis P, Daniels DJ (2019) The 100 most-cited articles about diffuse intrinsic pontine glioma: a bibliometric analysis. Childs Nerv Syst 35(12):2339-2346

26. MacDonald SM, Safai S, Trofimov A, Wolfgang J, Fullerton B, Yeap BY et al (2008) Proton radiotherapy for childhood ependymoma: initial clinical outcomes and dose comparisons. Int J Radiat Oncol Biol Phys 71(4):979-986

27. Mack SC, Taylor MD (2017) Put away your microscopes: the ependymoma molecular era has begun. Curr Opin Oncol 29(6):443-447

28. Makino K, Nakamura H, Yano S, Kuratsu J (2010) Populationbased epidemiological study of primary intracranial tumors in childhood. Childs Nerv Syst 26(8):1029-1034

29. Mansur DB (2013) Multidisciplinary management of pediatric intracranial ependymoma. CNS Oncol 2(3):247-257
30. Marinoff AE, Ma C, Guo D, Snuderl M, Wright KD, Manley PE et al (2017) Rethinking childhood ependymoma: a retrospective, multi-center analysis reveals poor long-term overall survival. J Neurooncol 135(1):201-211

31. Martinez-Perez R, Ung TH, Youssef AS (2021) The 100 mostcited articles on vestibular schwannoma: historical perspectives, current limitations, and future research directions. Neurosurg Rev

32. Massimino M, Miceli R, Giangaspero F, Boschetti L, Modena P, Antonelli M et al (2016) Final results of the second prospective AIEOP protocol for pediatric intracranial ependymoma. Neuro Oncol 18(10):1451-1460

33. McCain KW (2011) Eponymy and obliteration by incorporation: the case of the "Nash equilibrium." J Am Soc Inform Sci Technol 62(7):1412-1424

34. McCormick PC, Torres R, Post KD, Stein BM (1990) Intramedullary ependymoma of the spinal cord. J Neurosurg 72(4):523-532

35. Merchant TE, Li C, Xiong X, Kun LE, Boop FA, Sanford RA (2009) Conformal radiotherapy after surgery for paediatric ependymoma: a prospective study. Lancet Oncol 10(3):258-266

36. Merchant TE, Mulhern RK, Krasin MJ, Kun LE, Williams T, Li C et al (2004) Preliminary results from a phase II trial of conformal radiation therapy and evaluation of radiation-related CNS effects for pediatric patients with localized ependymoma. J Clin Oncol 22(15):3156-3162

37. Mork SJ, Loken AC (1977) Ependymoma: a follow-up study of 101 cases. Cancer 40(2):907-915

38. Oh MC, Kim JM, Kaur G, Safaee M, Sun MZ, Singh A et al (2013) Prognosis by tumor location in adults with spinal ependymomas. J Neurosurg Spine 18(3):226-235

39. Okonechnikov K, Mack SC, Kool M, Pfister SM, Pajtler KW (2018) Interrogating the enhancer landscape of intracranial ependymomas: perspectives for precision medicine. Exp Rev Prec Med Drug Dev 3(3):147-149

40. Pajtler KW, Mack SC, Ramaswamy V, Smith CA, Witt H, Smith A et al (2017) The current consensus on the clinical management of intracranial ependymoma and its distinct molecular variants. Acta Neuropathol 133(1):5-12

41. Pajtler KW, Pfister SM, Kool M (2015) Molecular dissection of ependymomas. Oncoscience 2(10):827-828

42. Pajtler KW, Witt H, Sill M, Jones DT, Hovestadt V, Kratochwil $F$ et al (2015) Molecular classification of ependymal tumors across all CNS compartments, histopathological grades, and age groups. Cancer Cell 27(5):728-743

43. Parker M, Mohankumar KM, Punchihewa C, Weinlich R, Dalton JD, Li Y et al (2014) C11 orf95-RELA fusions drive oncogenic $\mathrm{NF}-\kappa \mathrm{B}$ signalling in ependymoma. Nature 506(7489):451-455

44. Pavon LF, Capper D, Sibov TT, de Toledo SRC, Thomale UW, de Souza JG, et al (2019) New therapeutic target for pediatric anaplastic ependymoma control: study of anti-tumor activity by a Kunitz-type molecule, Amblyomin-X. Sci Rep;9(1):9973

45. Peeler CR, Mirkovic D, Titt U, Blanchard P, Gunther JR, Mahajan A et al (2016) Clinical evidence of variable proton biological effectiveness in pediatric patients treated for ependymoma. Radiother Oncol 121(3):395-401

46. Ramaswamy V, Hielscher T, Mack SC, Lassaletta A, Lin T, Pajtler KW et al (2016) Therapeutic impact of cytoreductive surgery and irradiation of posterior fossa ependymoma in the molecular era: a retrospective multicohort analysis. J Clin Oncol 34(21):2468-2477

47. Rousseau P, Habrand JL, Sarrazin D, Kalifa C, Terrier-Lacombe MJ, Rekacewicz C et al (1994) Treatment of intracranial ependymomas of children: review of a 15-year experience. Int $\mathrm{J}$ Radiat Oncol Biol Phys 28(2):381-386 
48. Salazar OM, Castro-Vita H, VanHoutte P, Rubin P, Aygun C (1983) Improved survival in cases of intracranial ependymoma after radiation therapy. J Neurosurg ;59(4):652

49. Shimoji K, Miyajima M, Karagiozov K, Yatomi K, Matsushima T, Arai H (2009) Surgical considerations in fourth ventricular ependymoma with the transcerebellomedullary fissure approach in focus. Childs Nerv Syst 25(10):1221-1228

50 Sonneland PR, Scheithauer BW, Onofrio BM (1985) Myxopapillary ependymoma. A clinicopathologic and immunocytochemical study of 77 cases. Cancer 56(4):883-893

51. Taylor MD, Poppleton H, Fuller C, Su X, Liu Y, Jensen P et al (2005) Radial glia cells are candidate stem cells of ependymoma. Cancer Cell 8(4):323-335

52. Tihan T, Zhou T, Holmes E, Burger PC, Ozuysal S, Rushing EJ (2008) The prognostic value of histological grading of posterior fossa ependymomas in children: a children's oncology group study and a review of prognostic factors. Mod Pathol 21(2):165-177

53. Toescu SM, Aquilina K (2019) Current and emerging methods of management of ependymoma. Curr Oncol Rep ;21(9):78

54. Tzaridis T, Milde T, Pajtler KW, Bender S, Jones DT, Müller $S$ et al (2016) Low-dose actinomycin-D treatment re-establishes the tumour suppressive function of P53 in RELA-positive ependymoma. Oncotarget 7(38):61860-61873
55. Villano JL, Parker CK, Dolecek TA (2013) Descriptive epidemiology of ependymal tumours in the United States. Br J Cancer 108(11):2367-2371

56. Wani K, Armstrong TS, Vera-Bolanos E, Raghunathan A, Ellison D, Gilbertson R et al (2012) A prognostic gene expression signature in infratentorial ependymoma. Acta Neuropathol 123(5):727-738

57. Witt H, Gramatzki D, Hentschel B, Pajtler KW, Felsberg J, Schackert G et al (2018) DNA methylation-based classification of ependymomas in adulthood: implications for diagnosis and treatment. Neuro Oncol 20(12):1616-1624

58. Wood H (2017) Neuro-oncology: a new approach to ependymoma subtyping. Nat Rev Neurol 13(9):512-513

59. Xi S, Sai K, Hu W, Wang F, Chen Y, Wang J, et al (2019) Clinical significance of the histological and molecular characteristics of ependymal tumors: a single institution case series from China. BMC Cancer;19(1):717

Publisher's note Springer Nature remains neutral with regard to jurisdictional claims in published maps and institutional affiliations. 